\title{
Managerial Learning from Analyst Feedback to Voluntary Capex Guidance, Investment Efficiency and Firm Performance
}

\author{
Jihun Bae \\ Erasmus School of Economics \\ Erasmus University Rotterdam \\ bae@ese.eur.nl \\ Gary C. Biddle* \\ Faculty of Business and Economics \\ University of Melbourne \\ g.biddle@unimelb.edu.au \\ Chul W. Park \\ Independent \\ acpark@gmail.com
}

October 10, 2020

Management Science forthcoming

*Corresponding Author

Key words: Voluntary guidance, analyst feedback, managerial learning, investment efficiency, firm performance

We very much appreciate helpful comments from the editor, associate editor, two anonymous reviewers, seminar participants at the American Accounting Association Annual Meetings, Erasmus University Rotterdam, KAIST-Korea University, Tilburg University, University of Hong Kong, and University of Melbourne. We also acknowledge and appreciate Institutional Investor Magazine All-America Research Team Awards data kindly shared by Michael Jung and StreetEvents data provided by the University of Melbourne Centre for Corporate Governance and Regulation and related expert data analysis kindly provided by James Peter Kavourakis. 


\title{
Managerial Learning from Analyst Feedback to Voluntary Capex Guidance, Investment Efficiency and Firm Performance
}

\begin{abstract}
We test predictions that managers issuing voluntary capex guidance learn from analyst feedback and that this learning enhances investment efficiency and firm performance (Langberg and Sivaramakrishnan, 2010). Our findings are consistent with these predictions. First, we find that managers' capex adjustments and capex guidance revisions relate positively with analyst feedback measured by differences between post-guidance analyst capex forecasts and managerial capex guidance. Second, changes in investment efficiency relate positively with analyst feedback. Third, subsequent firm financial performance relates positively with the predicted values of both managers' capex adjustments and capex guidance revisions. These findings extend prior evidence regarding sources of managerial learning and investment efficiency and help to explain the active issuance of voluntary guidance by managers in settings where, as for capex guidance, the potential for managerial learning from related share price effects is limited.
\end{abstract}




\section{Managerial Learning from Analyst Feedback to Voluntary Capex Guidance, Investment Efficiency and Firm Performance}

\section{Introduction}

To help explain why managers make voluntary disclosures when doing so exposes them to monitoring, analysis, and potentially negative short-run share price reactions, Langberg and Sivaramakrishnan (2010) model a two-way flow of information wherein voluntary disclosures by managers attract analyst feedback that informs more efficient investments that increase firm value. ${ }^{1}$ We empirically test these propositions for voluntary capital expenditure (capex) guidance, finding evidence that managers who issue such guidance learn from analyst feedback and that this learning enhances capital investment efficiency and firm financial performance. These findings extend prior evidence of managerial learning from share price reactions and help to explain why managers voluntarily issue guidance in settings, as for capex, where the potential to learn from share price reactions is limited, as we also explain.

Prior studies show that voluntary management disclosures can convey value-relevant information to capital markets (e.g., Healy and Palepu 2001) and that share price reactions to these disclosures can inform managers (e.g., Luo 2005; Chen et al. 2007; Bakke and Whited 2010; Jayaraman and $\mathrm{Wu} 2020) .{ }^{2}$ However, because share price reactions to voluntary managerial

\footnotetext{
${ }^{1}$ Because voluntary managerial disclosures can reveal new information to analysts, Langberg and Sivaramakrishnan (2010) argue that this provides incentives for analysts to process and augment this information that managers seek in order to inform value-creating decisions, and which analysts have incentives to provide to promote forecast accuracy (inclusive of managerial access). Per Langberg and Sivaramakrishnan (2010, p. 618), "We are assuming, of course, that financial analysts have access to multiple information sources and can inform both markets and managers with their information gathering and processing expertise", inclusive of any expected managerial learning.

${ }^{2}$ Luo (2005) finds that managers consider share price reactions to merger and acquisition announcements when making deal-closing decisions. Chen et al. (2007) and Bakke and Whited (2010) infer managerial learning from share prices in observed positive associations between investment share price sensitivity and private information contained in share prices. Complementing our focus on managerial learning from analyst feedback are two contemporaneous studies: Jayaraman and $\mathrm{Wu}(2020)$, which examines share price reactions to capex guidance issuance and capital expenditure adjustments, and Choi et al. (2020), which relates analyst feedback and investment efficiency via financing and monitoring channels (see Section 2).
} 
disclosures will reflect deviations from market expectations, value-creating managerial learning from share price reactions requires knowledge of these expectations as well as the marketperceived value-optimizing level. ${ }^{3}$ Thus, managers making voluntary disclosures have incentives to seek market feedback that can substitute for and help interpret related share price reaction to their disclosures. As modeled by Langberg and Sivaramakrishnan (2010), analysts are a natural source of such feedback.

Yet evidence supporting managerial learning from analysts is mixed. Studies by Hutton et al. (2012), Kadan et al. (2012) and Choi et al. (2020) argue that analysts' experience and expertise in assessing industry-level and macroeconomic factors may give them informational advantages over managers. Other studies argue that analysts are at an informational disadvantage relative to managers of firms in conditions of high operating leverage, inventory growth, and earnings loss; and/or that analysts merely transmit information from managers to markets (e.g., Hwang et al. 1996; Abarbanell and Lehavy 2003; Chen et al. 2007; Lehavy et al. 2011; Jayaraman and Wu 2020). Further largely unaddressed is whether managers learn from analyst feedback regarding capex guidance, as Langberg and Sivaramakrishnan (2010) propose. Thus, we treat managerial learning from voluntary disclosure feedback and learning-related effects on investment efficiency and firm performance as open empirical questions to address. ${ }^{4}$

\footnotetext{
${ }^{3}$ As further detailed in Section 2, a positive (negative) share price reaction to capex guidance (G) conveys only that $\mathrm{G}$ is closer (further) than the market's expectation of $\mathrm{G}$ to (from) a market-perceived value-optimizing capex level, but it does not in itself convey whether raising or lowering capex compared with $G$ will create value. To illustrate in capex levels, suppose that the market's expected capex guidance is 90 and the market-perceived value-optimizing capex is 100 . Negative share price reactions apply for $\mathrm{G}<90$, where raising capex above $\mathrm{G}$ creates value, and for a $\mathrm{G}$ level sufficiently greater than 100 (which we represent by G') where lowering capex below $G$ creates value. Positive share price reactions apply for $90<\mathrm{G}<100$, where raising capex above $G$ creates value, and for $100<\mathrm{G}<\mathrm{G}$ ' where lowering capex below $\mathrm{G}$ creates value. It follows that in order to infer from a share price reaction to $\mathrm{G}$ whether raising or lowering capex relative to $G$ will create value, a manager would need to learn both the market's expectation of $G$ and the market-perceived value-optimizing capex from other information sources.

${ }^{4}$ Appendices B and C provide examples of capex guidance and analyst feedback to capex guidance, respectively. Further anecdotal interview evidence from an analyst for the semiconductor sector lends support to our arguments and findings that managers revise capex plans to incorporate feedback from analysts.
} 
U.S.-listed firms voluntary issue capex guidance with a frequency and continuity comparable to that of earnings guidance. ${ }^{5}$ To help explain the motives for and effects of this active capex guidance issuance, we test empirically three predictions modeled by Langberg and Sivaramakrishnan (2010) relating managerial learning from analyst feedback, capital investment efficiency and firm performance. First, we test for managerial learning from analyst feedback by examining whether differences between post-guidance analyst capex forecasts and initial managerial capex guidance are positively related to managerial capex guidance forecast errors (hypothesis H1a) and managerial revisions to capex guidance (H1b). Second, we test whether changes in capital investment efficiency relate positively to post-guidance analyst feedback deviations from initial capex guidance $(\mathrm{H} 2)$. Third, we test whether firm financial performance relates positively to predicted values of managerial capex forecast errors (H3a) and guidance revisions (H3b).

We test these hypotheses using IBES Guidance data plus Compustat and CRSP data for a sample of 6,430 firm-year observations for U.S.-listed firms for fiscal years 2009 to 2014. To increase forecast term and content comparability, we define capex guidance firm-years as those in which a voluntary annual capex forecast is issued during the first quarter of the forecasted fiscal year. We define non-guidance firm-years as those not containing an annual capex forecast.

Consistent with predictions H1a and H1b, our empirical results show that differences between post-guidance analyst median capex forecasts and managerial capex guidance are positively associated with managerial capex guidance forecast errors and revisions of initial capex guidance, respectively. Consistent with $\mathrm{H} 2$, we find that investment efficiency changes are

\footnotetext{
${ }^{5}$ In our sample, $39 \%$ of firm-years exhibit capex guidance, $29 \%$ exhibit earnings guidance, and $92 \%$ of capex guidance firms exhibit no or only one break versus $97 \%$ for earnings guidance firms during the study period (see Table 1 for details).
} 
positively related with deviations of post-guidance median analyst capex forecasts from capex guidance. Consistent with $\mathrm{H} 3 \mathrm{a}$ and $\mathrm{H} 3 \mathrm{~b}$, we find positive associations between firm financial performance and predicted values of managerial capex forecast errors and guidance revisions, respectively. Thus, in a setting where the potential for managerial learning from share price reactions is limited, our evidence is consistent with managerial learning from analyst feedback to voluntary capex guidance that improves capital investment efficiency and enhances firm performance. Additional analyses, validity and robustness checks lend support to these findings. ${ }^{6}$

To provide assurance that our findings are attributable to managerial learning from analyst forecasts and not to managers and analysts using a common set of arising information, we test whether $\mathrm{H} 1$ results vary with three analyst expertise indicators: forecast diversity, firm-specific forecasting experience, and all-star analyst following (e.g., Choi et al. 2020) (Online Addendum [OA]-1.1), and with analyst informational advantage as indicated by investment synchronicity with macroeconomic and industry-level news (extending Hutton et al. 2012) (OA-1.2). We also test for greater managerial learning from analysts who issue unfavorable recommendations following the reasoning of Mayew et al. (2020) (OA-1.3). Results for H1 are found to be generally stronger for analysts with greater forecast expertise, firms with higher investment synchronicity, and analysts issuing unfavorable recommendations. To address whether our findings could be attributable to increased analyst monitoring, we estimate $\mathrm{H} 1$ regressions partitioned on indicators of agency conflict to find that both $\mathrm{H1a}$ and $\mathrm{H} 1 \mathrm{~b}$ also continue to hold in low agency conflict conditions $(\mathrm{OA}-2)$.

\footnotetext{
${ }^{6}$ Textual analyses of conference call transcript data in Section 5.1 show that negative-tone analyst capex questions relate positively with analyst feedback deviations and provide qualitatively similar findings for $\mathrm{H} 1$ and $\mathrm{H} 2$ when substituted for analyst feedback deviation. Applying the Biddle et al. (2009) conditional investment model to H2 in Section 5.2 reveals that managerial learning from analyst feedback to capex guidance helps mitigate both over- and under-investment. Tests of additional Langberg and Sivaramakrishnan (2010) predictions in OA-1.4 lend support to their model's descriptive validity. Six additional tables containing validity and robustness tests are presented in an Online Addendum described in Section 5.3.
} 
These findings contribute to several research streams. First, we extend prior evidence that managers making voluntary disclosures can learn from share price reactions (e.g., Luo 2005; Kau et al. 2008; Chen et al. 2007; Bakke and Whited 2010; Jayaraman and Wu 2020) to include managerial learning from analyst feedback where, as for capex, the potential for value-creating managerial learning from share price reactions is limited. As such, we add to a growing body of research indicating that analysts produce, gather and convey information beyond that otherwise available to managers and from which managers can learn (e.g., Hutton et al. 2012; Kadan et al. 2012; Choi et al. 2020), consistent with Langberg and Sivaramakrishnan's (2010) analytical predictions.

Second, we extend prior evidence that investment efficiency is enhanced by financial reporting quality (Biddle and Hilary 2006; Biddle et al. 2009; Chen et al. 2011) and managerial earnings guidance accuracy (Goodman et al. 2014) to include managerial learning from feedback to voluntary guidance reflected in analyst capex forecasts. Third, we augment prior evidence regarding whether management guidance promotes managerial short-termism and diminished firm performance (e.g., Fuller and Jensen 2002; Graham et al. 2005; Houston et al. 2010; Chen et al. 2011; Cheng et al. 2014) to indicate that voluntary capex guidance feedback can promote managerial learning that enhances longer-run investment efficiency and financial performance. Fourth, by providing evidence of firm value-enhancing managerial learning from analyst feedback (Langberg and Sivaramakrishnan 2010), our study helps to explain why managers of U.S.-listed firms issue voluntary capex guidance with a frequency and continuity comparable to that of earnings guidance.

Our paper is structured as follows. After this Introduction, in Section 2 we discuss prior studies and propose hypotheses. Section 3 describes our research design and tests. Section 4 
presents empirical results and Section 5 additional analyses and robustness checks. Section 6 summarizes our findings, which are subject of course to the inherent unobservability of managerial learning.

\section{Prior studies and hypotheses}

The analytical setting of Langberg and Sivaramakrishnan (2010) for which we empirically test envisions a two-way flow of information wherein managers' voluntary disclosures attract analyst feedback that informs more efficient investment and enhances firm value. This setting thus constitutes a confluence of several research streams including voluntary managerial disclosure, analyst feedback, investment efficiency, managerial learning, and value creation that we consider in turn.

Prior studies of voluntary forward-looking managerial disclosures have focused primarily on earnings or earning components guidance (Healy and Palepu 2001, Beyer et al. 2010), providing clear evidence that such guidance is reflected in contemporaneous share price reactions. Unclear is that this finding extends to capex guidance. Although earnings and capex guidance can both be argued to enhance transparency, timeliness and monitoring by enabling ex post comparisons with actual realizations, they differ in several important respects. First, capex is not implicitly directional like earnings in its firm value implications. Accordingly, whereas prior studies document positive relations between earnings guidance surprises and share returns (e.g., Pownall and Waymire 1989; Zuo 2016), evidence for capex guidance is mixed (Luo 2016; Jayaraman and Wu 2020). ${ }^{7}$ Second, capex provides considerable discretion for managerial adjustment based on

\footnotetext{
${ }^{7}$ Zuo (2016) finds that managers incorporate into earnings guidance revisions the information in share prices over the period from the day after initial earnings guidance date to one day before the guidance revision date. Jayaraman and $\mathrm{Wu}$ (2020) use differences in share price reactions to capex guidance to examine managerial learning from price feedback to capex guidance (see Section 2 below).
} 
analyst feedback whereas earnings, while to a degree discretionary, are subject to guiding internal and external audits, financial reporting requirements and regulatory oversight. Third, capex amounts and components are less readily observable than earnings and earnings components, some of which are separately forecasted by analysts (e.g., sales revenue). This discretion and opacity inherent in managerial capex decisions provide incentives for managers to create value by voluntarily issuing capex guidance and attracting analyst forecasts, analyses and feedback. This feedback can, in turn, inform managers' capex decisions (Langberg and Sivaramakrishnan, 2010).

Studies of capital investment efficiency indicate that it is enhanced by higher quality financial reporting (e.g., Biddle and Hilary 2006; Biddle et al. 2009; Chen et al. 2011), management forecast quality (e.g., Goodman et al. 2014) and accounting conservatism (e.g., Lara et al. 2016). Other studies provide evidence that investment efficiency is enhanced by analyst coverage and expertise (Firth et al. 2015; Chen et al. 2017; To et al. 2018; Brogaard et al. 2019; Choi et al. 2020) due to enhanced monitoring, information acquisition and price efficiency. ${ }^{8}$ Although these studies are suggestive of conditions conducive to managerial learning from analyst feedback, none directly tests for investment efficiency-enhancing managerial learning from analyst feedback to voluntary guidance issuance as predicted by Langberg and Sivaramakrishnan (2010).

Among studies that specifically examine capex guidance, Lu and Tucker (2012) argue that long-term institutional investor demand for monitoring should motivate voluntary capex disclosures by managers, but find only weak evidence for a relationship between the two. Luo (2016) estimates an accounting-variable-based model of optimal investment levels, finding that share prices decline when capital investments diverge from estimated optimal levels, though this

\footnotetext{
${ }^{8}$ To et al. (2018) and Brogaard et al. (2019) attribute relations between analyst coverage and investment efficiency to monitoring, information acquisition and price efficiency. Firth et al. (2015) and Chen et al. (2017) attribute relations between analyst expertise and investment efficiency to monitoring and information acquisition. Choi et al. (2020) relate analyst characteristics and investment efficiency via monitoring and financing channels.
} 
finding disappears for firms issuing capex guidance. ${ }^{9}$ Luo (2016) does not examine managerial learning or how it relates to capital investment efficiency.

Contemporaneous studies by Jayaraman and $\mathrm{Wu}(2020)$ and Choi et al. (2020) warrant closer consideration as they help motivate and complement our analysis. Jayaraman and $\mathrm{Wu}(2020)$ predict and find a positive relationship between share price reactions to capex guidance and capex adjustments, reasoning that "managers adjust capex investments upward (downward) when the market favorably (adversely) reacts to their forecasts." Although this reasoning is analogous to good news/bad news share price reactions to earnings guidance, it does not follow for capex guidance because, unlike earnings, capex is not implicitly directional in its firm value implications. Rather, share price reactions to capex guidance reflect how issued guidance relates to both market expectations of the managerial guidance, which analyst capex forecasts serve to illustrate, and the market-perceived value-optimizing capex. As such, share price reactions cannot in themselves indicate whether upward or downward capex adjustments will create value. ${ }^{10}$ As illustrated in footnote 3, a manager would need to know both the market's guidance expectation and the marketperceived value-optimizing capex level in order to infer from a share price reaction whether raising or lowering capex from guidance will create value. A manager who knows the market's guidance expectation and the sign of a share price reaction to guidance could infer whether the marketperceived value-optimizing capex is higher or lower than guidance but would require additional information to infer the market-perceived value-optimizing capex level. Thus, managers have incentives to seek feedback to their capex guidance that can substitute for and help interpret share

\footnotetext{
${ }^{9}$ We similarly find (untabulated) that analysts' capex forecast revisions around capex guidance are positively related to the capex guidance surprise consistent with analysts learning from managements when preparing their capex forecasts. This finding complements our focus on learning, suggesting that it is both present and bi-directional.

${ }^{10}$ Another reason why share price reactions to capex guidance are challenging to interpret empirically is that they are often issued jointly with earning guidance. In our sample, $72.2 \%$ of capex guidance observations are issued jointly with earnings announcements, $29.9 \%$ are issued jointly with earnings guidance, and $26.2 \%$ are issued jointly with both earnings announcements and earnings guidance.
} 
price reactions, with analysts a natural source for this feedback as modeled by Langberg and Sivaramakrishnan (2010). ${ }^{11}$

A concurrent study by Choi et al. (2020) complements our analysis by corroborating a precondition for managerial learning from analyst feedback to managerial capex guidance. Specifically, Choi et al. (2020) show that analyst capex forecasts contain information that can help facilitate more efficient capital investments, thereby countervailing other evidence that analysts are informationally disadvantaged relative to managers (e.g., Hwang et al. 1996; Abarbanell and Lehavy 2003; Chen et al. 2007; Lehavy et al. 2011) and/or that they merely "forecast actual rather an optimal capex" (Jayaraman and Wu 2020, p. 7). Whereas Choi et al. (2020) do not directly examine nor test for managerial learning from analyst feedback to capex guidance, their findings that analyst capex forecast informativeness relates to analyst abilities and that the presence of capex forecasts helps mitigate both over- and under-investment (e.g., Biddle et al. 2009) are consistent with the potential for managerial learning from analyst feedback to capex guidance, which is our focus. ${ }^{12}$ Our analysis complements Choi et al. (2020) by examining interactions between managerial and analyst capex forecasts for evidence of managerial learning as a mechanism by which information contained in analyst capex forecasts comes to be reflected in

\footnotetext{
${ }^{11}$ It further follows that post-guidance analyst capex forecasts will reflect the degree to which analysts expect managerial learning from capex guidance feedback to influence managerial capex decisions.

${ }^{12}$ Choi et al. (2020) examine the information content of analyst capex forecasts by relating investment efficiency to the presence or absence of managerial and analyst forecasts. We use Choi et al. (2020) findings regarding analyst ability and industry knowledge in confirmatory tests for managerial learning. Choi et al. (2020) findings that positive (negative) growth signals incrementally mitigate capital under- (over-)investment are consistent with managerial learning and with related firm performance enhancements for which we also test. We also allow for information asymmetry and control for associated financing and monitoring effects that Choi et al. (2020) document so as to isolate the separate effects of managerial learning from analyst feedback to capex guidance as modeled by Langberg and Sivaramakrishnan (2010).
} 
investment decisions, thus also helping to explain why managers and analysts are motivated to voluntarily issue capex forecasts. ${ }^{13}$

Mirroring later empirical findings that analyst capex forecasts contain information useful for investment decisions (Hutton et al. 2012; Kadan et al. 2012; Choi et al. 2012), the Langberg and Sivaramakrishnan (2010) model "captures the notion that knowledge of firm-specific information alone is not enough for efficient decision making - the manager must also understand the implications of the environment that is external to his organization" (p. 605). Their model applies readily to voluntary capex guidance issuance wherein managers may subject themselves to monitoring and analysis in order to stimulate information production and gathering by analysts and resulting feedback learning creates firm value by enhancing the efficiency of their capital investment decisions. ${ }^{14}$

Langberg and Sivaramakrishnan (2010) also identify managerial forecasting ability as a factor that determines the value of voluntary guidance, where managerial forecast accuracy is an indicator of managerial competence. They further consider a condition where managers are ex ante fully informed and thus lack incentive to seek analyst feedback to enhance investment efficiency, implying that firms not issuing guidance could be more efficient than guidance firms. Managers also could use information possessed or conveyed privately by analysts to pursue personal gains by choosing inefficient rather than efficient capital investments for empire building (i.e., overinvestment) (Stulz 1990), leading a quiet life (i.e., underinvestment) (Bertrand and

\footnotetext{
${ }^{13}$ Prior studies confirm that earnings forecast accuracy is an important performance indicator that affects analyst career advancement (Hong et al. 2000; Hong and Kubik 2003). It follows that in the presence of managerial learning, analysts motivated to forecast earnings and capex accurately will reflect in their capex forecasts expected managerial learning. To the degree analysts expect incomplete managerial learning, it will bias against our findings.

${ }^{14}$ Management capex guidance thus motivates new information production by analysts, thereby helping to explain why managers provide it. A related reason is greater informativeness for investment decisions that arises from managers and analysts sharing their insights.
} 
Mullainathan 2003), or otherwise pursuing investments not indicated by the information they hold. Thus, voluntarily issuing capex guidance may help discipline investment choices by facilitating monitoring and feedback that inform and incentivize more efficient capital investments, but it is an empirical question as to whether value reducing or value creating incentives dominate.

To test predictions that follow from the Langberg and Sivaramakrishnan (2010) model, we consider three related hypotheses. First, if managers learn from analyst feedback to capex guidance and adjust capital expenditures accordingly, we predict that managerial capex guidance forecast errors (i.e., the differences between actual capital expenditures and capex guidance) and managerial capex guidance revisions will relate positively to analyst feedback reflected in differences between post-guidance analyst capex forecasts and managerial capex guidance, expressed as $\mathrm{H} 1 \mathrm{a}$ and $\mathrm{H} 1 \mathrm{~b}$ respectively, both in alternative form:

H1a: Managerial capex guidance forecast errors are positively associated with differences between post-guidance analyst capex forecasts and capex guidance.

H1b: Managerial capex guidance revisions are positively associated with differences between post-guidance analyst capex forecasts and capex guidance.

If analysts expected no investment efficiency-enhancing managerial learning from their feedback to capex guidance, post-guidance analyst capex forecasts would conform with capex guidance and there would be no association between analyst feedback and investment efficiency. However, if analysts expect investment efficiency-enhancing managerial learning, post-guidance analyst capex forecasts will diverge from capex guidance and relate positively with investment efficiency. Applying this reasoning, following from $\mathrm{Hla}, \mathrm{H} 1 \mathrm{~b}$ and the Langberg and Sivaramakrishnan (2010) modeling, we predict that post-guidance analyst capex forecasts that 
deviate more from managerial capex guidance will enhance capital investment efficiency to a greater degree, as expressed in alternative form in hypothesis $\mathrm{H} 2$ :

H2: Capital investment efficiency changes are positively related to post-guidance analyst capex forecast deviations from capex guidance.

As further follows from the Langberg and Sivaramakrishnan (2010) model, voluntary managerial disclosures that attract feedback and inform more efficient investments will also enhance firm performance reflected in firm value. We focus on firm financial performance to better reflect realized (versus expected) performance effects attributable to managerial learning from analyst feedback to capex guidance. ${ }^{15}$ Following Chen et al. (2007) and Jayaraman and Wu (2020) we measure financial performance using period ahead return on assets $(R O A)$ and operating cash flows scaled by assets $(C F O)$. To isolate components of capex adjustments more reflective of managerial learning from analyst feedback, these financial performance measures are related to predicted values of managerial capex forecast errors and guidance revisions, expressed respectively as $\mathrm{H} 3 \mathrm{a}$ and $\mathrm{H} 3 \mathrm{~b}$ in alternative form as follows:

H3a: Firm financial performance is positively related to the predicted values of capex forecast errors.

H3b: Firm financial performance is positively related to the predicted values of capex guidance revisions.

\footnotetext{
${ }^{15}$ While Langberg and Sivaramakrishnan (2010) model firm value effects, in our empirical setting these can reflect other information, for example, market reactions to earnings guidance issued jointly with capex guidance for $72.2 \%$ of our firm-year observations (op. cit. footnote 10).
} 


\section{Research design}

\subsection{Sample selection and data collection}

To test our hypotheses, we utilize IBES Guidance capex and earnings guidance data for years 2008 to 2014 , where 2008 is the first full year of IBES capex guidance availability. ${ }^{16}$ Accounting and financial data are obtained from the Compustat/CRSP merged database. Institutional investor ownership data are obtained from Thomson Reuters. Following prior research, we exclude utilities $(4800 \leq \mathrm{SIC} \leq 4999)$ and financial firms $(6000 \leq \mathrm{SIC} \leq 6999)$, as these firms are subject to possibly confounding disclosure and regulatory regimes. We require capex guidance firms to have analyst capex forecasts within six months prior to the issuance of capex guidance and we require non-capex guidance firms to have analyst capex forecasts within six months before the announcement date of the prior-year earnings to control for managerial learning from analysts in the absence of capex guidance. These criteria provide a study sample of 6,430 firm-year observations. ${ }^{17}$

Figure 1 presents a timeline wherein a manager voluntarily issues capex guidance, analysts subsequently issue capex forecasts, the manager issues revised capex guidance, and actual capital expenditures (and thus capex error) are reported. We limit our annual capex guidance sample firms to those that issue quantitative forecasts (i.e., point or range) during the first quarter of the forecast

\footnotetext{
${ }^{16}$ Because some regression tests employ an indicator variable for prior-year capex guidance, the sample period for our multivariate tests effectively begins in calendar year 2009.

${ }^{17}$ To address the possibility that capex guidance amounts might include acquisition or R\&D expenditures in addition to capital expenditures, we compare capex guidance amounts in our sample with actual capital expenditures, acquisition expenditures, and R\&D expenditures obtained from cash flow statements. We find that the mean absolute capex forecast error (i.e., absolute difference between actual capex and capex guidance scaled by beginning of year net property, plant and equipment) is $0.071,0.220,0.346$, and 0.508 when we define actual capex as (1) actual capital expenditures, (2) the sum of actual capital expenditures and R\&D expenditures, (3) the sum of actual capital expenditures and acquisition expenditures, and (4) the sum of actual capital expenditures, R\&D and acquisition expenditures, respectively. Thus, capex guidance relates most closely to actual capital expenditures exclusive of acquisition and R\&D expenditures. In addition, Compustat generally reports sales of property, plant and equipment separately from capital expenditures, implying that capital expenditures in Compustat generally measure gross purchases of property, plant and equipment.
} 
target year. ${ }^{18}$ Our reasoning is that managers issuing this guidance would know prior-year actual capital expenditures, thus making the guidance more credible and subject to analyst scrutiny and feedback. We exclude from our guidance sample forecasts issued after the end of the first quarter because these forecasts are likely to reflect actual capital expenditures executed during the first quarter and potentially subsequent quarters, which would introduce measurement error into planned capital investment. If a firm does not issue any capex guidance for the target year during this 12-month period that ends at the end of the target year, it is assigned to the non-guidance group; if it issues capex guidance only after the first fiscal quarter of the forecasting target year, we exclude it from both the capex guidance group and the non-guidance group.

To measure analyst feedback to voluntary managerial capex guidance, we use the difference between the post-guidance median analyst capex forecast and initial managerial capex guidance. The analyst median capex forecast is measured as the median of all individual analyst capex forecasts issued between one day after the management guidance date and one day before the subsequent quarterly earnings announcement date or the management capex forecast revision date, whichever is earlier. ${ }^{19}$ This measurement period better ensures that post-guidance analyst capex forecasts reflect initial managerial capex guidance and not analyst learning from subsequent earnings announcements and managerial capex guidance revisions.

\footnotetext{
${ }^{18}$ Among our guidance sample, $85 \%$ issued only one capex forecast during the first fiscal quarter. If a firm issued more than one capex forecasts during the first quarter, we identify the first as initial guidance and our results are robust to excluding observations that issued multiple forecasts during the first quarter. Among capex guidance observations in the universe of IBES Guidance database from which we draw our sample, $53.4 \%$ are point guidance and $43.0 \%$ are range guidance; thus, $96.4 \%$ are in the form of quantitative guidance. In our study sample of 2,507 quantitative capex guidance observations, $52.1 \%(47.9 \%)$ are point (range) guidance. An analysis of the universe of IBES Guidance reveals that capex guidance firms on average provide guidance 2.7 times over the 12-month period through the end of the forecast target year. For capex guidance issued over this 12-month period, we find that the first guidance is issued within the last nine months of the period for $20 \%$ and within the first three months of the period for $80 \%$.

${ }^{19} \mathrm{We}$ choose the earnings announcement date instead of the 10-Q date because the earliest disclosure date of actual quarterly capital expenditures is likely to be the earnings announcement date. We do not use analysts' consensus forecast of capex compiled by IBES Summary file because it might be tainted by some stale forecasts.
} 


\subsection{Anecdotal evidence regarding analyst feedback to capex guidance}

Prior studies indicate that, as sophisticated users of financial information motivated to provide accurate earnings forecasts, analysts project future earnings after taking into account expected capital investment (e.g., Brown et al. 2019; Chapman and Green 2018; Huang et al. 2017). ${ }^{20}$ To provide initial anecdotal evidence of related information exchanges between analysts and managers, we randomly selected 50 calls in our capex guidance sample and examined the scripts with several findings (see Example 4 in Appendix B). First, managers present capex guidance before analysts requested it in 41 of the 50 cases. Second, management guidance refers to "capex", "capital expenditure", "capital spending", and/or "capital budget" in all cases, but the terms planned property, plant and equipment (PP\&E) expenditures, acquisition by capital lease, and planned spending on M\&A or research and development (R\&D) are rarely used. Examples of capex guidance discussions during the earnings conference calls in Example 4 indicate that managers use "capex" to mean gross purchases of PP\&E excluding expected proceeds from PP\&E disposals, which are difficult to reliably estimate prior to actual disposals, consistent with our discussion in footnote 17. In four of 50 cases, executives discuss acquisitions or R\&D expenditures in addition to capital expenditures, but these discussions relate to post-acquisition outcomes, expenses or financing costs or product development as a result of past versus future R\&D. Third, 25 of 50 cases indicate follow-up discussions after initial presentations of capex plans. ${ }^{21}$ Brown et al. (2019) further find that some analysts are selected to receive a private "call-back" from investor relations officers after conference calls and these targeted call-backs may give analysts more opportunities to provide capex guidance feedback. Another channel for analyst feedback regarding efficient capital investments is media coverage as illustrated in Examples 1 and 2 of Appendix C.

\footnotetext{
${ }^{20}$ Fully developed research notes of sell-side analysts generally include projected financial statements.

${ }^{21}$ In Section 5.1, we report the results of conference call textual analysis for our entire sample of capex guidance firms.
} 
This evidence combined supports an active interchange between managers and analysts regarding capex guidance, consistent with managerial learning conducive to efficient capital investment as modeled by Langberg and Sivaramakrishnan (2010).

\subsection{Empirical test specifications}

Hypotheses $\mathrm{H1a}$ and $\mathrm{H} 1 \mathrm{~b}$ predict respectively that capex guidance forecast errors (i.e., differences between actual capex and initial capex guidance) and managers' capex guidance revisions are positively associated with differences between post-guidance analyst capex forecasts and capex guidance. We test these predictions using Equation (1):

$$
\begin{aligned}
\text { CPXGD_ERR }_{i, t} & (\text { or CPXGD_REV } \\
& \left.=\beta_{0}\right) \\
& +\beta_{1} F E E D B A C K_{i, t}+\beta_{2} I N D C P X G R O W T H_{i, t}+\beta_{3} C P X G R O W T H_{-} Q 1_{i, t} \\
& +\beta_{4} C A R_{-} 5 D A Y_{i, t}+\text { Industry FE }+ \text { Year FE }+ \text { Industry*Year FE } \\
& +\varepsilon_{i, t}
\end{aligned}
$$

where $C P X G D_{-} E R R\left(C P X G D_{-} R E V\right)$ is actual capital expenditure (revised capex guidance) minus initial capex guidance, divided by beginning of year net property, plant and equipment, multiplied by 100. Analyst feedback (FEEDBACK) is measured as the difference between post-guidance analyst median capex forecast and capex guidance divided by beginning of year net property, plant and equipment, multiplied by 100 . To control for overall direction of industry-level investment, we include industry-mean capex growth (INDCPXGROWTH). In our research design, managers' initial guidance is issued in the first quarter of the forecasting target year and analyst feedback is collected during the period between one day after the guidance date and one day before the subsequent quarterly earnings announcement date or the management capex forecast revision date, whichever is earlier. Given this timeline, capex guidance forecast errors and managers' capex guidance revisions could reflect information realized in the first quarter not conveyed in 
managerial learning from analyst feedback. To control for this possibility, we include capex growth in the first quarter relative to the same quarter of the previous year (CPXGROWTH_Q1). We also control for Jayaraman and Wu (2020)'s stock price feedback variable (i.e., CAR_5DAY). We measure CAR_5DAY using standardized (i.e., standardized to have a mean of zero and a standard deviation of one) cumulative abnormal returns over the five days surrounding the capex guidance date following Jayaraman and $\mathrm{Wu}$ (2020). We compute abnormal returns by subtracting returns on the S\&P 500 index from the firm's raw stock returns. H1a and H1b predict that $\beta_{1}$ is positive.

$\mathrm{H} 2$ predicts a positive association between capital investment efficiency changes and deviations of post-guidance analyst capex forecasts from capex guidance. To estimate capital investment efficiency, we assume that a firm's expected or normal investment is determined by investment opportunities (e.g., Modigliani and Miller 1969; Hayashi 1982). Following McNichols and Stubben (2008), we include two variables in our expected investment model: (1) Tobin's Q at the beginning of the year to capture a firm's investment opportunities and (2) current-year operating cash flows to control for constraints on investment due to internal financing capability. We assume that these two variables in combination parsimoniously determine expected investment. $^{22,23}$ Specifically,

\footnotetext{
${ }^{22}$ McNichols and Stubben (2008) include Tobin's Q, prior-year asset growth and operating cash flows, and prior-year investment in their augmented normal investment model. We do not include prior-year asset growth and prior-year investment in our baseline normal investment model because prior-year investment directly contributes to prior-year asset growth and because prior-year investment consists of normal and abnormal investment and the second component may act as a measurement error. Our results are nonetheless robust to including prior-year asset growth and prior-year investment in the normal investment model.

${ }^{23}$ Prior literature uses cash holdings, firm size, firm age and leverage as additional financial constraint variables to capture the difficulty of raising cash for funding investment (Fazzari et al. 1988; Hubbard 1998; Richardson 2006). We add these variables excluding leverage, which may also induce under-investment (Myers 1977), to the baseline normal investment model, with our results qualitatively robust to this change. Cash holdings are measured as the balance of cash and short-term investments deflated by total assets at the beginning of the year. Firm size is the $\log$ of total assets at the beginning of the year. Firm age is the log of the number of years the firm has been listed on Compustat at the beginning of the year.
} 


$$
C P X_{i, t}=\beta_{0}+\beta_{1} T O B I N Q_{i, t-1}+\beta_{2} C F_{i, t}+\varepsilon_{i, t},
$$

where $C P X_{i, t}$ is capital expenditures scaled by beginning of year net property, plant and equipment for firm i in year t, multiplied by 100 , and $T O B I N Q_{i, t-1}$ is beginning of year Tobin's $\mathrm{Q}$ and $C F_{i, t}$ is current-year operating cash flows. To allow that firms within industries can experience correlated booms and busts, we pool all the sample observations and estimate abnormal investment using Equation (2). The magnitude of the residual in Equation (2) (i.e., deviation of actual capex from predicted capex or abnormal investment) captures the extent of capital investment inefficiency. A positive deviation from normal investment indicates overinvestment and a negative deviation from normal investment indicates underinvestment. A larger magnitude of the absolute value of abnormal investment represents less efficiency in capital investment.

To test $\mathrm{H} 2$, we measure changes in investment efficiency of guidance firms by subtracting investment efficiency of capex guidance from that of actual capital expenditures. To control for investment efficiency changes attributable to managerial learning from revisions in analyst capex forecasts in the absence of managerial capex guidance, we employ non-guidance firms' analyst forecast revisions as a control in our research design. ${ }^{24}$ We measure non-guidance firms' pseudo capex guidance as analysts' median capex forecast prior to the annual earnings announcement date and analysts' pseudo feedback as the revision in analysts' median capex forecasts around the earnings announcement date. ${ }^{25}$ We measure the change in capital investment efficiency of non-

\footnotetext{
${ }^{24}$ Using changes in the number of following analysts as an exogenous shock, Brogaard et al. (2019) find analyst forecast revisions relate positively with capital investment efficiency, a pre-condition for managerial learning potential that we directly test.

${ }^{25}$ Specifically, the forecast revision is measured as the difference between the median of all the earliest individual analyst forecasts issued in the period from one day after the annual earnings announcement date to one day before the subsequent quarterly earnings announcement date and the median of all the latest individual analyst forecasts issued in the six-month period prior to the annual earnings announcement date.
} 
guidance firms by subtracting investment efficiency of pseudo capex guidance from investment efficiency of actual capital expenditures. We then use the following equation to test $\mathrm{H} 2$ :

$$
\begin{aligned}
& \text { INVEFF_DIFF_ACTUAL_MF } F_{i, t} \\
& =\beta_{0}+\beta_{1} \text { FEEDBACK_DEV } V_{i, t}+\beta_{2} \text { PSEUDOFEEDBACK_DEV } V_{i, t} \\
& +\beta_{3} \text { CHGEPSGD }_{i, t-1}+\beta_{4} \text { CHGEPSGD }_{i, t-1} * \text { CHGEPSGACC }_{i, t-1} \\
& +\beta_{5} \text { CHGINSTOWN }_{i, t-1}+\beta_{6} \text { CHGANALYST }_{i, t-1}+\beta_{7} \text { CHGFRQ }_{i, t-1} \\
& +\beta_{8} \text { CHGLEV }_{i, t-1}+\beta_{9} \text { CHGFREECF }_{i, t-1}+\beta_{10} \text { CHGSTDCPX }_{i, t-1} \\
& +\beta_{11} \text { CHGTOBINQ } Q_{i, t-1}+\beta_{12} C_{H G C F}+\text { Industry FE }+ \text { Year FE } \\
& + \text { Industry } * \text { Year } F E+\varepsilon_{i, t} \text {, }
\end{aligned}
$$

where INVEFF_DIFF_ACTUAL_MF is the difference of investment efficiency between actual capital expenditures and capex guidance for guidance firms (or pseudo capex guidance for nonguidance firms). We estimate investment efficiency of capex guidance, pseudo capex guidance, and actual capex by using the absolute value of the deviation of capex guidance, pseudo capex guidance, and actual capex, respectively, from normal capex estimated by Equation (2). We scale the absolute deviation by beginning of year net property, plant and equipment, multiplied by -1 . Normal capex is estimated using the parameters of estimated Equation (2) and beginning of year TOBIN's $Q$ and current-year operating cash flow. FEEDBACK_DEV is the absolute value of the difference between the post-guidance analyst capex forecast and managers' initial capex guidance divided by beginning of year net property, plant and equipment, multiplied by 100 for a guidance firm and zero for a non-guidance firm. PSEUDOFEEDBACK_DEV is the absolute value of the difference between the post-pseudo-guidance analyst capex forecast and pseudo capex guidance (i.e., analyst capex forecast revisions around the announcement date of prior-year earnings) divided by beginning of year net property, plant and equipment, multiplied by 100 for a nonguidance firm and zero for a guidance firm. We add changes in control variables, which affect 
investment efficiency according to prior literature (see Section OA-3 in Online Addendum for detailed discussion of these control variables), in line with the difference form of the dependent variable. The coefficient on FEEDBACK_DEV $\left(=\beta_{1}\right)$ captures the effect of analyst feedback on investment efficiency changes before controlling for the effect of analyst capex forecast revisions on investment efficiency changes in the absence of management capex guidance, which is captured by the coefficient on PSEUDOFEEDBACK_DEV $\left(=\beta_{2}\right)$. H2 predicts the difference between $\beta_{1}$ and $\beta_{2}\left(=\beta_{1}-\beta_{2}\right)$ to be positive in Equation (3).

To test H3, following Chen et al. (2007) and Jayaraman and $\mathrm{Wu}$ (2020), we examine the association between managerial capex adjustments and firm financial performance measured by subsequent year return on assets $(R O A)$ and operating cash flows scaled by assets $(C F O)$ using Equation (4):

$$
\begin{aligned}
R O A(C F O)_{i, t+1} & \\
& =\beta_{0}+\beta_{1} \text { PredCPXGD_ERR } R_{i, t}\left(\text { PredCPXGD_REV } V_{i, t}\right)+\beta_{2} L O G M V_{i, t} \\
& +\beta_{3} B T M_{i, t}+\beta_{4} R O A_{i, t}+\beta_{5} C F O_{i, t}+\text { Industry FE }+ \text { Year FE } \\
& + \text { Industry } * \text { Year } F E+\varepsilon_{i, t},
\end{aligned}
$$

To better isolate components of managerial capex adjustments reflecting learning from analyst feedback, we relate $R O A$ and $C F O$ to predicted values of managerial forecast errors and managerial capex guidance revisions estimated using Equation (1). H3 predicts positive coefficients for PredCPXGD_ERR and PredCPXGD_REV (i.e., for predicted values of capex adjustments and guidance revisions following analyst feedback to capex guidance, respectively). In all test regressions, we include year, industry, and industry*year fixed effects. ${ }^{26}$ To mitigate the influence of outliers, we winsorize all continuous variables at the $1 \%$ and $99 \%$ levels. ${ }^{27}$

\footnotetext{
${ }^{26}$ Test results for $\mathrm{H} 1, \mathrm{H} 2$ and $\mathrm{H} 3$ are robust to including firm- and year-fixed effects.

${ }^{27}$ We test our hypotheses using a one-tailed test because our hypotheses predict signs for our variables of interest. If ambiguity is inherent in the prediction of these signs, our tests could be overinterpreted.
} 


\section{Empirical results}

\subsection{Univariate test results}

Table 1 describes the study sample. Panel A presents proportions of voluntary capex and earnings guidance, revealing a greater incidence of capex guidance than earnings guidance. Specifically, $39 \%$ of sample firm-years contain capex guidance, $29 \%$ contain earnings guidance, and $16 \%$ contain both. ${ }^{28,29}$ Panel B of Table 1 presents sample distributions of capex guidance and earnings guidance by year, revealing stable frequencies of around $39 \%$ and $29 \%$ each year, respectively. Panel C presents sample distributions of capex guidance and earnings guidance by industry. Capital intensive industries such as Extractive and Textiles show relatively higher capex guidance frequencies. All industries except Computers, Durable Manufacturers, Services, and Pharmaceuticals report significantly higher frequencies of capex guidance than earnings guidance. We speculate that the lower frequencies of capex guidance for computer and pharmaceutical firms may reflect that the costs of revealing new technology investments to competitors may outweigh gains from analyst feedback to capex guidance.

Panel D of Table 1 presents the number of breaks in capex guidance after disclosing capex guidance for at least one year during the study period. Among total sample firms $55.4 \%$ have no breaks after the year they disclose capex guidance, indicating that more than half of the sample firms continue issuing capex guidance once they begin. Panel E of Table 1 presents the corresponding number of breaks in earnings guidance, revealing capex guidance to be nearly as

\footnotetext{
${ }^{28}$ By comparison, Lu and Tucker (2012) report for their hand-collected sample for fiscal 2005 that $57 \%$ provide earnings guidance and $37 \%$ provide capex guidance. Luo (2016) reports for his IBES sample that $29.4 \%$ report earnings guidance and $27.7 \%$ report capex guidance.

${ }^{29}$ To confirm the reliability of IBES Guidance data, we randomly selected 100 observations from our study sample that contain capex guidance but not earnings guidance. Examining their original press releases or conference calls, we found that all were correctly coded, with five firms containing EBITDA or operating earnings guidance, but not earnings guidance, as indicated.
} 
continuous as earnings guidance (with $92 \%$ versus $97 \%$ of firms showing 0 or 1 break during the study period, respectively). Overall, Table 1 shows that U.S.-listed firms voluntarily disclose capex guidance with greater frequency and nearly equal continuity as earnings guidance.

[Insert Table 1 here]

Table 2 presents summary statistics for test variables including those contained in the Online Addendum. Capex guidance firms are seen to exhibit more earnings guidance, higher analyst followings, higher dissemination media coverage, higher investment efficiency, higher profitability, higher institutional ownership, higher financial reporting quality, lower litigation risk, lower investment volatility, lower share return volatility, higher capital intensity, higher leverage, lower free cash flow and lower growth opportunities compared with non-guidance firms.

[Insert Table 2 here]

\subsection{Tests of hypotheses}

\subsubsection{H1 - Analyst feedback, capex guidance forecast errors and capex guidance revisions}

Hypotheses $\mathrm{H} 1 \mathrm{a}$ and $\mathrm{H} 1 \mathrm{~b}$ predict that capex guidance forecast errors and capex guidance revisions are positively associated with analyst feedback as measured by the difference between the post-guidance analyst median forecast and capex guidance, respectively. In other words, managers learn from analyst feedback and adjust actual or planned capital expenditures accordingly, consistent with the reasoning of Langberg and Sivaramakrishnan (2010). Columns (1) and (2) of Table 3 report estimation results using capex guidance forecast errors and capex guidance revisions, respectively. Sample size decreases from 6,430 to 2,117 and 1,708 because we limit sample firm-year observations to those with data for initial capex guidance and subsequent analyst median capex forecasts for Column (1) plus revised managerial capex guidance for Column 
(2), respectively. ${ }^{30}$ Results show that capex forecast errors are significantly and positively associated with the level of analyst feedback regarding capex guidance $(0.576, p$-value $<0.01)$, consistent with H1a. Capex guidance revisions are significantly and positively associated with the level of analyst feedback regarding capex guidance $(0.057, p$-value $<0.01)$, consistent with $\mathrm{H} 1 \mathrm{~b} .{ }^{31}$ Results for control variables indicate that capex guidance forecast errors and capex guidance revisions are positively related to growth in first-quarter firm-level investment relative to that of the prior year same quarter. ${ }^{32,33}$ Thus, these findings lend support to both H1a and H1b.

[Insert Table 3 here]

\subsubsection{H2 - Analyst feedback and investment efficiency changes}

Table 4 presents results for multivariate tests of $\mathrm{H} 2$, which predicts that capital investment efficiency changes are positively related to deviations of post-guidance analyst capex forecasts from capex guidance. We use as the dependent variable for guidance (non-guidance) firms' differences between capital investment efficiency based on actual capital expenditures and capex guidance (pseudo capex guidance). We find for Equation (3) a positive significant coefficient for analyst feedback deviation $\left(F E E D B A C K_{-} D E V, 0.510, p\right.$-value $\left.<0.01\right)$ that is significantly larger $(p$-value $<0.01)$ than the positive significant coefficient for pseudo deviating feedback $(0.108, p$ -

\footnotetext{
${ }^{30}$ In our sample, we find that managers revise their initial capex forecasts on average 1.7 times a year.

${ }^{31}$ The standardized coefficients show that capex forecast errors (capex guidance revisions) increase by a $0.36(0.12)$ standard deviation when the feedback increases by a one standard deviation.

${ }^{32}$ We additionally include annual changes in Tobin's $Q$ to control for changes in investment opportunities. The results remain qualitatively identical.

${ }^{33}$ We find a positive coefficient on CAR_5DAY but unlike Jayaraman and $\mathrm{Wu}(2020)$, we find it insignificant. This discrepancy may be due to several differences in research design including that: (1) our dependent variables CPXGD_ERR and CPXGD_REV use net property, plant and equipment as a scaler whereas Jayaraman and $\mathrm{Wu}(2020)$ use capex guidance as a scaler; (2) Jayaraman and Wu (2020) exclude observations that concurrently issue management earnings forecasts on the capex guidance date whereas we include these observations; and (3) Jayaraman and $\mathrm{Wu}(2020)$ 's sample uses all capex guidance including revised capex guidance whereas our study focuses on initial capex guidance during the first fiscal quarter. In untabulated results, our $\mathrm{H} 1$ finding still holds with a significantly positive coefficient on $C A R \_5 D A Y$ when we use the Jayaraman and $\mathrm{Wu}(2020)$ 's dependent variable and their research design that excludes observations with concurrent management earnings forecasts.
} 
value $<0.10$ ) as predicted by $\mathrm{H} 2 .{ }^{34}$ This finding indicates that greater deviations of post-guidance analyst forecasts from managerial capex guidance are associated with managerial learning from feedback more conducive to capital investment efficiency. ${ }^{35}$

[Insert Table 4 here]

\subsubsection{H3 - Capex adjustments, guidance revisions and firm performance}

Table 5 presents findings for $\mathrm{H} 3 \mathrm{a}$ and $\mathrm{H} 3 \mathrm{~b}$ that predict positive associations between firm financial performance and predicted values of managerial capex adjustments and guidance revisions following analyst feedback. $\mathrm{H} 3 \mathrm{a}$ and $\mathrm{H} 3 \mathrm{~b}$ thus predict positive coefficients for PredCPXGD_ERR and PredCPXGD_REV, respectively. Consistent with these predictions, Table 5 reports strongly positive coefficients for both PredCPXGD_ERR $(0.001, p$-value $<0.01)$ and PredCPXGD_REV $(0.000, p$-value $<0.01)$, thus lending support to managerial learning from analyst feedback that enhances firm performance. ${ }^{36}$

[Insert Table 5 here]

\section{Corroborating analyses, validity and robustness checks}

\subsection{Textual analysis of analyst capex question tone during conference calls}

To provide corroborative evidence that managerial learning from capex guidance feedback can arise from interactions with analysts, we conduct a textual analysis of conference call transcripts over the period from one day before the announcement date of prior-year earnings until

\footnotetext{
${ }^{34}$ The standardized coefficient shows that changes of investment efficiency increase by 0.17 standard deviation when analysts' feedback deviation increases by one standard deviation.

${ }^{35} \mathrm{We}$ include annual changes in industry-mean investment efficiency to control for industry-wide changes in investment efficiency. Separately, we include annual changes in Tobin's Q to control for changes in investment opportunities. Our results remain robust to inclusion of these change variables.

${ }^{36}$ The standardized coefficients show that $R O A_{t+1}$ increases by a $0.07(0.16)$ standard deviation when the predicted capex forecast errors (predicted capex guidance revisions) increases by a one standard deviation. $C F O_{t+1}$ increases by a 0.04 (0.11) standard deviation when the predicted capex forecast errors (predicted capex guidance revisions) increases by a one standard deviation.
} 
two days before the revision date of capex guidance for guidance firms (two days before announcement dates of first-quarter earnings for non-guidance firms). For all firms in our sample, we identify from the StreetEvents database all analyst question paragraphs containing "capex", “capex expenditure”, “capital investment”, “capital spend”, “capital budget”, “capital project”, and "capital expense" and then code the tone of those containing questions regarding managerial capex guidance following the Loughran and McDonald Sentiment Word Lists (Loughran and McDonald 2011). ${ }^{37}$ Specifically, we count each question paragraph of the Q\&A session during a conference call as a unit of question and measure the number of questions on capex guidance (QUEST_NUM). If the question has at least one negative-tone word, it is counted as a negative-tone question (NEGTONEQUEST_NUM). We also define indicator variables for the questions $\left(Q U E S T \_D\right)$ and negative-tone questions (NEGTONEQUEST_D) to capture question and negative-tone question incidence, respectively.

Panel A of Table 6 presents descriptive statistics for analyst questions and tone for the guidance and non-guidance sample. Results show that analysts of guidance firms tend to ask more questions ( 0.703 versus 0.229 times) and more negative-tone questions ( 0.299 versus 0.095 times) consistent with managers of capex guidance firms receiving more analyst feedback. Results are similar when we use dummy variables that capture incidences of capex guidance questions $($ QUEST_D) and negative-tone questions (NEGTONEQUEST_D). Panel B of Table 6 reports results from regressing analyst feedback deviation on the incidence of analyst negative-tone questions after controlling for variables capturing information environment (firm size $L O G M V$ and the number of analysts $A N A L Y S T$ ), growth (the market-to-book ratio $M T B$ ), capex intensity (CAPINT), capex uncertainty $(S T D C P X)$ and capex guidance form (an indicator for a range or

\footnotetext{
${ }^{37}$ Example 3 of Appendix $\mathrm{C}$ shows examples of analyst questions regarding capex guidance during earnings
} conference calls. 
point forecast $\left.R A N G E C P X_{-} D\right) .{ }^{38}$ These results indicate that analyst feedback deviation is positively related to analyst negative-tone capex question incidence consistent with the potential for managerial learning from conference call feedback. Control variable results indicate that analyst feedback deviation is greater when capex intensity is lower, capex volatility is higher, and when capex guidance takes the form of a range. ${ }^{39}$

Panel C of Table 6 presents results from testing H1 using NEGTONEQUEST_D instead of FEEDBACK. Variables that can have signed values in Equation (1) are modified to take the form of absolute value because, unlike FEEDBACK which has a signed value, NEGTONEQUEST_D is non-directional. Panel C reports that estimated coefficients on NEGTONEQUEST_D are both positive in Columns (1) and (2) but significant only for Column (2) for capex guidance revisions. When conditioned on the incidence of a managerial revision in capex guidance ( $\left.C P X G D_{-} R E V \_D\right)$ in Panel D, the coefficient on NEGTONEQUEST_D*CPXGD_REV_D is positive and significant indicating that guidance-revision firms make larger investment adjustments after feedback containing negative-tone analyst capex questions. The results in Panels $\mathrm{C}$ and $\mathrm{D}$ are thus consistent with managerial learning from analyst conference call feedback. Panel E of Table 6 presents results from testing $\mathrm{H} 2$ using NEGTONEQUEST_D in place of FEEDBACK_DEV, with qualitatively identical results consistent with analyst capex question tone informing investment efficiency.

[Insert Table 6 here]

\footnotetext{
${ }^{38}$ We find that analyst feedback deviation is greater for range forecasts than for point forecasts (difference $=0.947$, $p$-value $<0.01)$. This result suggests that a range-form capex guidance is an indication that managers are more receptive to analyst feedback.

${ }^{39}$ When we include both positive- and negative-tone feedback in the regression on Panel B of Table 6, we find an insignificant relation between positive-tone feedback (POSTONEQUEST_D) and analyst feedback deviation (FEEDBACK_DEV) whereas the relation between negative-tone feedback (NEGTONEQUEST_D) and analyst feedback deviation (FEEDBACK_DEV) remains significantly positive. These results show that negative and positive tone are indicative of analysts' disagreement and agreement with managers' capex guidance.
} 


\subsection{Biddle et al. (2009) conditional investment model applied to H2}

A conditional investment model proposed by Biddle et al. (2009) implies for $\mathrm{H} 2$ that analyst feedback will mitigate both over- and under-investment when the firm is in a condition of being more likely to over- or under-invest, respectively. To incorporate conditions of over- and under-investment, we follow Biddle et al. (2009) to rank firms into deciles for each of two partition variables: cash balances and leverage multiplied by minus one. Ranks of each variable are scaled between zero and one and these scaled values are averaged to create OVERFIRM, which has a value between zero and one.

H2 in the context of Biddle et al.'s (2009) conditional setting predicts that when overinvestment (under-investment) is more likely, analyst feedback informing reduced (increased) capex is likely to be followed by a decrease (increase) in actual investment. To test this prediction we create three feedback dummy variables based on the signs of the analyst feedback (= postguidance analyst median capex forecast - capex guidance): incidence of feedback informing increased, unchanged, and reduced capex (i.e., FEEDBACK_INC, FEEDBACK_ZERO and FEEDBACK_DEC, respectively). Table 7 reports that, when under-investment is more likely, the incidence of analysts' feedback informing increased capex is positively associated with actual investment $\left(F E E D B A C K \_I N C=0.013, p\right.$-value $\left.<0.05\right)$, and when over-investment is more likely, the incidence of analysts' feedback informing decreased investment is negatively associated with actual investment $($ FEEDBACK_DEC + OVERFIRM*FEEDBACK_DEC $=-0.010, p$-value $<$ 0.05). ${ }^{40}$ Combined, these findings lend support to analyst capex feedback improving investment efficiency by helping to mitigate both over- and under-investment.

\footnotetext{
${ }^{40}$ The coefficient on FEEDBACK_DEC is significantly positive, indicating that analyst feedback informing reduced investment in the situation where underinvestment is more likely is not heeded by managers.
} 
[Insert Table 7 here]

\subsection{Additional analyses, validity and robustness checks contained in On-line Addendum}

For expositional brevity, six additional tables are presented in an Online Addendum (OA) containing additional analyses, validity and robustness tests that lend support to and extend our findings as follows. ${ }^{41}$

OA-1. Cross-sectional validity tests for H1a and H1b confirming that:

OA-1.1 Results generally vary positively with analyst forecast diversity, experience, and all-star analyst (e.g., Choi et al. 2020), thus providing evidence that our findings are not attributable to managers and analysts using arising commonly available information;

OA-1.2. Analyst feedback to managerial capex guidance is more informative when analysts have an informational advantage over managers as measured by investment synchronicity with macroeconomic and industry-level news (extending Hutton et al. 2012);

OA-1.3. Managerial learning is greater from analysts who issue unfavorable recommendations consistent with the reasoning of Mayew et al. (2020);

OA-1.4. Additional Langberg and Sivaramakrishnan (2010) empirical predictions are largely valid for our sample regarding managers' forecasting competence, managers' longhorizon incentive, and bad news, thus lending support to analytical model construct validity;

$\mathrm{OA}-2$. $\mathrm{H} 1 \mathrm{a}$ and $\mathrm{H} 1 \mathrm{~b}$ results remain valid for a low agency cost subsample, thus providing evidence that findings are not attributable to analyst monitoring of agency conflicts; and

OA-3. Our investment efficiency model is insensitive to simultaneous equations estimation and Granger causality, and the test results of $\mathrm{H} 2$ are robust to the use of a capital over- and

\footnotetext{
${ }^{41}$ Of 21 statistical tests presented in the Online Addendum, 18 are in predicted directions, 16 of which are statistically significant, one is not in the predicted direction and statistically insignificant, and two are not in predicted directions with possible explanations indicated.
} 
under-investment model following Biddle et al. (2009).

\section{Summary and discussion}

We present evidence consistent with analytical predictions by Langberg and Sivaramakrishnan (2010) that managers voluntarily issue capex guidance to attract analyst feedback that informs more efficient investment decisions thereby enhancing firm performance. Consistent with managerial learning from this feedback, we find that both managerial capex guidance forecast errors and managerial capex guidance revisions relate positively to differences between post-guidance analyst capex forecasts and capex guidance. Consistent with investment efficiency being enhanced by managerial learning from analyst feedback, we find that investment efficiency changes relate positively to deviations of post-guidance analyst capex forecasts from capex guidance. Consistent with managerial learning that enhances firm performance, we find that both predicted values of managerial forecast errors and guidance revisions relate positively with firm financial performance. Additional analyses, validity and robustness tests considering conference call analyst capex question tone, conditional investment model, analyst expertise, analyst information advantage, analyst managerial access and feedback informativeness, and validity of investment efficiency model, lend support to these findings. While our findings are consistent with managerial learning from analyst feedback to voluntary managerial capex guidance, managerial learning itself is inherently unobservable, and therefore, readers should, of course, interpret these findings cautiously.

Our findings extend several related literatures. First, we provide evidence extending motives for and effects of voluntary disclosures by managers to include net benefits beyond increased monitoring and transparency. These net benefits help to explain why managers of U.S.listed firms issue capex guidance with a frequency and continuity comparable to that of earnings 
guidance. Second, our findings lend support to active managerial learning from analysts beyond prior evidence of managerial learning from share prices. This helps explain why managers issue capex guidance in settings where the potential for managerial learning from share price effects is limited and incentives for managers to learn from analysts (and analysts from managers) arise. Third, we extend prior evidence that investment efficiency is enhanced by financial reporting quality and managerial earnings guidance accuracy to include managerial learning from analyst feedback to managers' voluntarily issued capex guidance. Finally, we augment prior evidence that earnings guidance can promote managerial short-termism and diminished firm performance to indicate that voluntarily issued capex guidance can serve, via managerial learning, to enhance longer-term investment efficiency and firm financial performance. 


\section{References}

Abarbanell J, Lehavy R (2003) Predict earnings management and analysts' earnings forecast errors? J. Accounting Res. 41(1):1-31.

Bakke TE, Whited TM (2010) Which firms follow the market? An analysis of corporate investment decisions. Rev. Fin. Stud. 23(5):1941-1980.

Bertrand M, Mullainathan S (2003) Enjoying the quiet life? Corporate governance and managerial preferences. J. Political Econom. 111(5):1043-1075.

Beyer A, Cohen DA, Lys TZ, Walther BR (2010) The financial reporting environment: Review of the recent literature. J. Accounting Econom. 50(2):296-343.

Biddle GC, Hilary G (2006) Accounting quality and firm-level capital investment. Accounting Rev. 81(5):963-982.

Biddle GC, Hilary G, Verdi RS (2009) How does financial reporting quality relate to investment efficiency? J. Accounting Econom. 48(2):112-131.

Brogaard J, Shi W, Wei KCJ, You H (2019) Do analyst improve investment efficiency? Working paper, University of Washington, Seattle.

Brown LD, Call AC, Clement MB, Sharp NY (2019) Managing the narrative: Investor relations officers and corporate disclosure. J. Accounting Econom. 67(1):58-79.

Chapman K, Green JR (2018) Analysts' influence on managers' guidance. Accounting Rev. 93(1):45-69.

Chen Q, Goldstein I, Jiang W (2007) Price informativeness and investment sensitivity to stock price. Rev. Fin. Stud. 20(3):619-650.

Chen F, Hope O-K, Li Q, Wang X (2011) Financial reporting quality and investment efficiency of private firms in emerging markets. Accounting Rev. 86(4):1255-1288.

Chen W, Hribar P, Melessa S (2018) Incorrect inferences when using residuals as dependent variables. J. Accounting Res. 56(3):751-796.

Chen S, Matsumoto DA (2006) Favorable versus unfavorable recommendations: The impact on analyst access to management-provided information. J. Accounting Res. 44(4):657-89.

Chen S, Matsumoto C, Rajgopal S (2011) Is silence golden? An empirical analysis of firms that stop giving quarterly earnings guidance. J. Accounting Econom. 51(1):134-150.

Chen T, Xie L, Zhang Y (2017) How does analysts' forecast quality relate to corporate investment efficiency? J. Corp. Finance 43:217-240.

Cheng M, Subramanyam KR, Zhang Y (2014) Earnings guidance and managerial myopia. Working paper, University of Arizona, Tucson.

Choi JK, Hann RN, Subasi M, Zheng Y (2020) An empirical analysis of analysts' capital expenditure forecasts: Evidence from corporate investment efficiency. Contemporary Accounting Res. https://doi.org/10.1111/1911-3846.12597. 
Edmans, A, Goldstein I, Jiang W. (2015) Feedback effects, asymmetric trading, and the limits to arbitrage. Amer. Econom. Rev. 105:3766-3797.

Fazzari SM, Hubbard RG, Petersen BC (1988) Financing constraints on corporate investment. Brookings Papers on Economic Activity:141-195.

Feng M, McVay S (2010) Analysts' incentives to overweight management guidance when revising their short-term earnings forecasts. Accounting Rev. 85(5):1617-1646.

Firth, M, Xie L, Zhang Y (2015) How do analysts' forecast characteristics relate to investment efficiency? Working paper, Lingnan University.

Francis J, Philbrick D, Schipper K (1994) Shareholder litigation and corporate disclosures. J. Accounting Res. 32(2):137-164.

Fuller J, Jensen MC (2002) Just say no to Wall Street: Putting a stop to the earnings game. J. Appl. Corp. Fin. 14(4):41-46.

Goodman TH, Neamtiu M, Shroff N, White HD (2014) Management forecast quality and capital investment decisions. Accounting Rev. 89(1):331-365.

Gopalan R, Milbourn T, Song F, Thakor AV (2014). Duration of executive compensation. $J$. Finance, 69(6):2777-2817.

Graham JR, Harvey CR, Rajgopal S (2005) The economic implications of corporate financial reporting. J. Accounting Econom. 40(1):3-73.

Greene WH (2000) Econometric analysis (Prentice Hall, Englewood Cliffs, NJ).

Hayashi F (1982) Tobin's marginal q and average q: A neoclassical interpretation. Econometrica 50(1):213-224.

Healy PM, Palepu KG (2001) Information asymmetry, corporate disclosure, and the capital markets: A review of the empirical disclosure literature. J. Accounting Econom. 31(1):405440.

Hong H, Kubik JD (2003) Analyzing the analysts: Career concerns and biased earnings forecasts. J. Finance. 58 (1):313-351.

Hong H, Kubik JD, Solomon A (2000) Security analysts' career concerns and herding of earnings forecasts. Rand J. Econom. 31(1):121-144.

Houston JF, Lev B, Tucker JW (2010) To guide or not to guide? Causes and consequences of stopping quarterly earnings guidance. Contemporary Accounting Res. 27(1):143-185.

Huang AH, Lehavy R, Zhang AY, Zheng R (2017) Analyst information discovery and interpretation roles: A topic modeling approach. Management Sci. 64(6):2833-55.

Hubbard RG (1998) Capital-market imperfections and investment. J. Econom. Lit. 36:193-225.

Hutton AP, Lee LF, Shu SZ (2012) Do managers always know better? The relative accuracy of management and analyst forecasts. J. Accounting Res. 50(5):1217-1244. 
Hwang L, Jan CL, Basu S (1996) Loss firms and analysts' earnings forecast errors. J. Fin. Stmt. Anal. 1(2):18-30.

Jayaraman S, Wu JS (2020) Should I Stay or Should I Grow? Using Voluntary Disclosure to Elicit Market Feedback. Rev. Financial. Stud. 33(8):3854-3888.

Jensen MC (1986) Agency costs of free cash flow, corporate finance, and takeovers. Amer. Econom. Rev. 76(2):323-329.

Kadan O, Madureira L, Wang R, Zach T (2012) Analysts' industry expertise. J. Accounting Econom. 54(2-3):95-120.

Kau JB, Linck JS, Rubin PH (2008) Do managers listen to the market? J. Corp. Finance. 14(4):347-362.

Kothari SP, Leone AJ, Wasley CE (2005) Performance matched discretionary accrual measures. J. Accounting Econom. 39(1):163-197.

Langberg N, Sivaramakrishnan K (2010) Voluntary disclosures and analyst feedback. J. Accounting Res. 48(3):603-646.

Lara, JMG, Osma BG, Penalva, F. (2016) Accounting conservatism and firm investment efficiency. J. Accounting Econom. 61(1):221-238.

Lehavy R, Li R, Merkley K (2011) The effect of annual report readability on analyst following and the properties of their earnings forecasts. Accounting Rev. 86(3):1087-1115.

Lin HW, McNichols MF (1998) Underwriting relationships, analysts' earnings forecasts and investment recommendations. J. Accounting Econom. 25(1):101-27.

Loughran T, McDonald B (2011) When is a liability not a liability? Textual analysis, dictionaries, and 10-Ks. J. Finance. 66(1):35-65.

Lu H-Y, Tucker JW (2012) Nonearnings corporate guidance. Financial. Mgt. 41(4):947-977.

Luo Y (2005) Do insiders learn from outsiders? Evidence from mergers and acquisitions. $J$. Finance. 60(4):1951-1982.

Luo J (2016) The stock price reaction to investment news: New evidence from modeling optimal capex and capex guidance. Working paper, New York University.

Maddala GS (1983) Limited dependent and qualitative variables in econometrics. Cambridge University Press London, UK.

Matsumoto DA (2002) Management's incentives to avoid negative earnings surprises. Accounting Rev. 77(3):483-514.

Mayew WJ, Sethuraman M, Venkatachalam M (2020) Individual Analysts' Stock Recommendations, Earnings Forecasts, and the Informativeness of Conference Call Question and Answer Sessions. Accounting Rev. 0000-0000.

McNichols MF, Stubben SR (2008) Does earnings management affect firms' investment decisions? Accounting Rev. 83(6):1571-1603. 
Michaely R, Womack KL (1999) Conflict of interest and the credibility of underwriter analyst recommendations. Rev. Financial. Stud. 12(4):653-86.

Modigliani F, Miller MH (1969) Reply to Heins and Sprenkle. Amer. Econom. Rev. 59(4):592595.

Myers SC (1977) Determinants of corporate borrowing. J. Financial Econom. 5(2):147-175.

Pinto JE, Robinson TR, Stowe JD (2019) Equity valuation: A survey of professional practice. $R$. Fin. Econom. 37(2):219-33.

Pownall G, Waymire G (1989) Voluntary disclosure credibility and securities prices: Evidence from management earnings forecasts. J. Accounting Res. 27(2):227-45.

Richardson S (2006) Over-investment of free cash flow. Rev. Accounting Stud. 11(2-3):159-189.

Stulz R (1990) Managerial discretion and optimal financing policies. J. Fin. Econom. 26(1):3-27.

To TY, Navone M, Wu E (2018) Analyst coverage and the quality of corporate investment decisions. J. Corp. Finance 51:164-181.

Zhang, Y., \& Gimeno, J. (2016) Earnings pressure and long-term corporate governance: Can longterm-oriented investors and managers reduce the quarterly earnings obsession?. Organization Sci. 27(2):354-372.

Zuo L (2016) The informational feedback effect of stock prices on management forecasts. $J$. Accounting Econom. 61(2):391-413. 


\section{Appendix A. Variable definitions}

INVEFF

EPSGD

CPXGD

INSTOWN

ANALYST

FRQ

LEV

FREECF

STDCPX

STDRET

CAPINT

$R O A$

MTB

RISKIND

DISSEM_MEDIA

CPXGD_ERR

CPXGD_REV

FEEDBACK

INDCPXGROWTH
$=$ Investment efficiency measured by the absolute value of residuals multiplied by -1 from the following model from McNichols and Stubben (2008) using OLS regression for the pooled sample;

$$
C P X_{i, t}=\beta_{0}+\beta_{1} T O B I N Q_{i, t-1}+\beta_{2} C F_{i, t}+\varepsilon_{i, t}
$$

$=$ Indicator variable equal to one if firm issues earnings guidance for target year $t$ during the first quarter of fiscal year $t$, and zero otherwise;

$=$ Indicator variable equal to one if firm issues capex guidance for target year $t$ during the first quarter of fiscal year $t$, and zero otherwise;

$=$ Ratio of shares owned by institutional investors divided by total shares outstanding;

$=\log$ of $(1+$ number of following analysts $)$;

$=$ Financial reporting quality measured by the absolute residual from the discretionary accrual model of Kothari et al. (2005), multiplied by -1 ;

$=$ Ratio of total debt to total assets;

$=$ The level of free cash flow when it is positive and zero otherwise. Free cash flow is measured by (operating cash flow + investing cash flow + long-term debt issuance - long-term debt reduction + changes in current debt) / beginning of year net property, plant and equipment;

$=$ Standard deviation of $C P X$ from the past three years;

$=$ Standard deviation of monthly share returns over three-year period prior to the beginning of the fiscal year, subject to a minimum of 20 return observations;

$=$ Capital intensity measured by net property, plant and equipment divided by total assets;

$=$ Return on assets measured by net income before extraordinary items divided by total assets;

$=$ Market to book ratio;

$=$ Indicator variable equal to one if a firm is from a high litigation risk industry defined by SIC codes for biotechnology (2833-2836 or 87318734), computer hardware (3570-3577), electronics (3600-3674), retailing (5200-5961), computer software (7370-7374), and zero otherwise;

$=$ Indicator variable equal to one if a firm's prior-year first-quarter capex guidance generated at least one relevant news flash article in RavenPack's Dow Jones Edition database with a relevance score of at least 100, and zero otherwise;

$=$ Actual capital expenditure minus initial capex guidance divided by beginning of year net property, plant and equipment, multiplied by 100 ;

$=$ Updated managerial capex guidance subsequent to post-guidance analysts' capex forecasts minus initial managerial capex guidance divided by beginning of year net property, plant and equipment, multiplied by 100 ;

$=$ Analyst median capex forecast issued after managerial capex guidance minus managerial capex guidance divided by beginning of year net property, plant and equipment, multiplied by 100 ;

$=$ Mean value of annual $C P X$ growth calculated by SIC 2-digit industry level; 


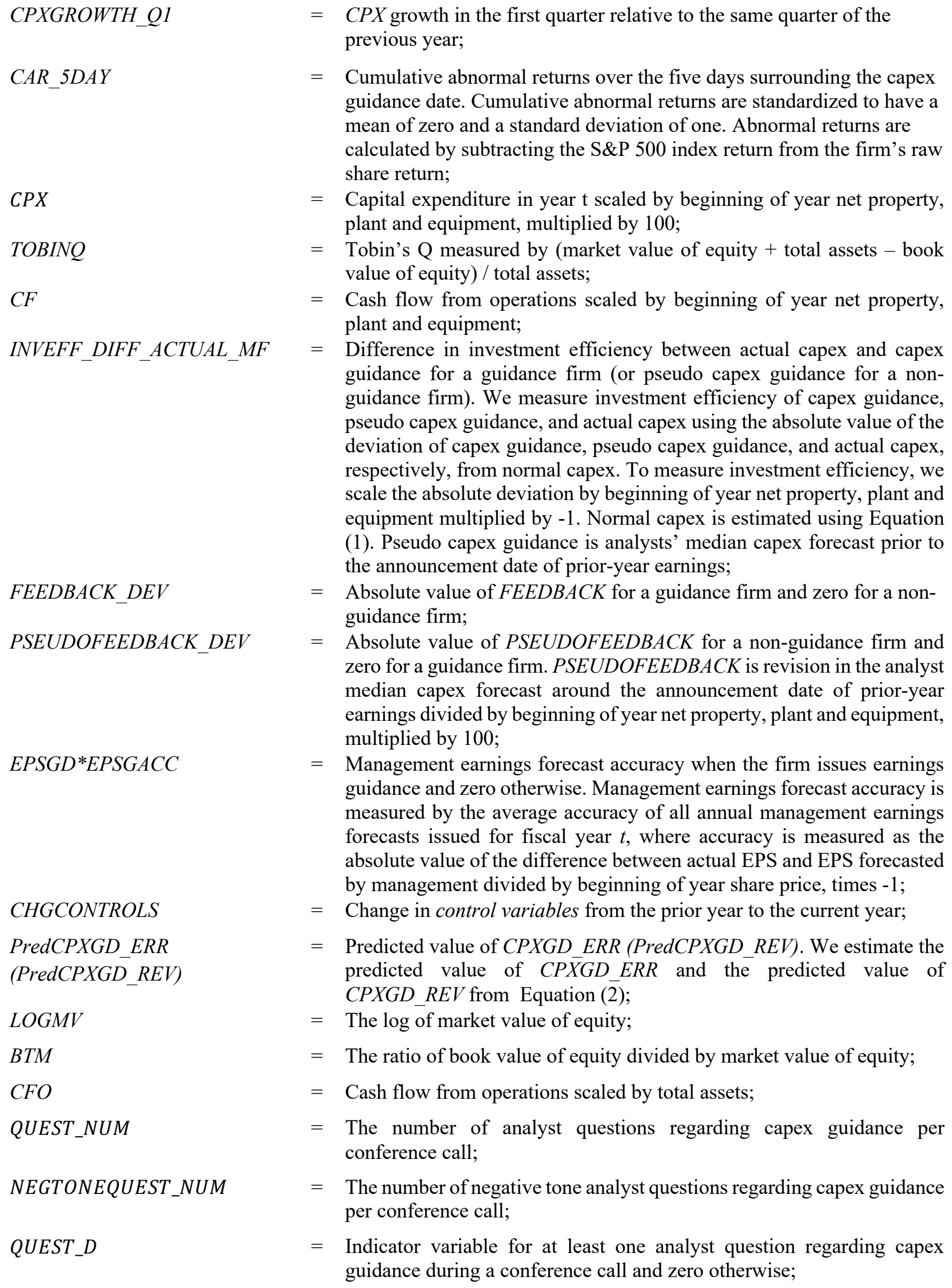

$=C P X$ growth in the first quarter relative to the same quarter of the previous year;

$=$ Cumulative abnormal returns over the five days surrounding the capex guidance date. Cumulative abnormal returns are standardized to have a mean of zero and a standard deviation of one. Abnormal returns are calculated by subtracting the S\&P 500 index return from the firm's raw share return;

$=$ Capital expenditure in year $\mathrm{t}$ scaled by beginning of year net property, plant and equipment, multiplied by 100 ;

$=$ Tobin's $\mathrm{Q}$ measured by (market value of equity + total assets - book value of equity) / total assets;

$=$ Cash flow from operations scaled by beginning of year net property, plant and equipment;

$=$ Difference in investment efficiency between actual capex and capex guidance for a guidance firm (or pseudo capex guidance for a nonguidance firm). We measure investment efficiency of capex guidance, pseudo capex guidance, and actual capex using the absolute value of the deviation of capex guidance, pseudo capex guidance, and actual capex, respectively, from normal capex. To measure investment efficiency, we scale the absolute deviation by beginning of year net property, plant and equipment multiplied by -1 . Normal capex is estimated using Equation (1). Pseudo capex guidance is analysts' median capex forecast prior to the announcement date of prior-year earnings;

$=$ Absolute value of FEEDBACK for a guidance firm and zero for a nonguidance firm;

$=$ Absolute value of PSEUDOFEEDBACK for a non-guidance firm and zero for a guidance firm. PSEUDOFEEDBACK is revision in the analyst median capex forecast around the announcement date of prior-year earnings divided by beginning of year net property, plant and equipment, multiplied by 100 ;

$=$ Management earnings forecast accuracy when the firm issues earnings guidance and zero otherwise. Management earnings forecast accuracy is measured by the average accuracy of all annual management earnings forecasts issued for fiscal year $t$, where accuracy is measured as the absolute value of the difference between actual EPS and EPS forecasted by management divided by beginning of year share price, times -1 ;

$=$ Change in control variables from the prior year to the current year;

$=$ Predicted value of $C P X G D \_E R R$ (PredCPXGD_REV). We estimate the predicted value of $C P X G D_{-} E R R$ and the predicted value of $C P X G D \_R E V$ from Equation ( $\left.\overline{2}\right)$;

$=$ The log of market value of equity;

$=$ The ratio of book value of equity divided by market value of equity;

$=$ Cash flow from operations scaled by total assets;

$=$ The number of analyst questions regarding capex guidance per conference call;

$=$ The number of negative tone analyst questions regarding capex guidance per conference call;

$=$ Indicator variable for at least one analyst question regarding capex guidance during a conference call and zero otherwise; 


\begin{tabular}{|c|c|}
\hline NEGTONEQUEST_D & $\begin{aligned}= & \text { Indicator variable for at least one negative tone analyst question } \\
& \text { regarding capex guidance during a conference call and zero otherwise; }\end{aligned}$ \\
\hline$A B S C P X G D \_E R R$ & Absolute value of $A B S C P X G D \_E R R$; \\
\hline$A B S C P X G D \_R E V$ & Absolute value of $A B S C P X G D \_R E V$; \\
\hline$C P X G D \_R E V \_D$ & $\begin{array}{l}\text { Indicator variable for the incidence of capex guidance revision and zero } \\
\text { otherwise; }\end{array}$ \\
\hline$C A P X$ & $\begin{array}{l}\text { Capital expenditure in year } \mathrm{t} \text { scaled by beginning of total asset, } \\
\text { multiplied by } 100 \text {; }\end{array}$ \\
\hline OVERFIRM & $\begin{array}{l}\text { A ranked variable to measure the likelihood of over-investment. We } \\
\text { rank firms into deciles for each of two partition variables: their cash } \\
\text { balance and their leverage multiplied by minus one. Ranks of each } \\
\text { variable are scaled between zero and one; }\end{array}$ \\
\hline FEEDBACK_DEC (ZERO, INC) & $\begin{array}{l}\text { Indicator variable equal to one if analyst median capex forecast issued } \\
\text { after managerial capex guidance is greater (equal or smaller) than } \\
\text { managerial capex guidance; }\end{array}$ \\
\hline$L O G A T$ & The log of total assets; \\
\hline STDCFO & $\begin{array}{l}=\text { Standard deviation of operating cash flow scaled by beginning of total } \\
\text { asset in the past three years; }\end{array}$ \\
\hline STDSALES & $\begin{array}{l}\text { Standard deviation of sales scaled by beginning of total asset in the past } \\
\text { three years; }\end{array}$ \\
\hline ZSCORE & $\begin{array}{l}\text { Altman's z-score calculated by the following formula: } 3.3^{*} \text { Pretax } \\
\text { income }+ \text { Sales }+0.25^{*} \text { Retained earnings }+0.5^{*} \text { (current assets }- \text { current } \\
\text { liabilities)/total assets; }\end{array}$ \\
\hline KSTRUCTURE & $\begin{array}{l}\text { The ratio of long-term debt to the sum of long-term debt and market } \\
\text { value of equity; }\end{array}$ \\
\hline INDKSTRUCTURE & SIC 3-digit level industry mean of KSTURCTURE; \\
\hline CFO_S & The ratio of cash flow from operations to sales; \\
\hline$D I V$ & $\begin{array}{l}=\text { Indicator variable that equals one if the firm declares dividends and zero } \\
\text { otherwise; }\end{array}$ \\
\hline FIRMAGE & $\begin{array}{l}\text { Natural } \log \text { of the difference between the first year when the firm } \\
\text { appears in Compustat and the current year; }\end{array}$ \\
\hline OPCYCLE & $\begin{array}{l}\text { Natural log of the firm's operating cycle calculated by the following } \\
\text { formula: (average accounts receivables/sales)*360+(average } \\
\text { inventory/cost of goods sold)*360; }\end{array}$ \\
\hline LOSS & $\begin{array}{l}\text { Indicator variable that equals one if net income before extraordinary } \\
\text { items is negative, and zero otherwise; }\end{array}$ \\
\hline
\end{tabular}


Appendix B: Examples of capex guidance

\section{Example 1: Quest Diagnostics Reports Fourth Quarter And Full Year 2012 Financial Results; Announces 2013 Guidance [Excerpted, Emphasis Added]}

23 January, 2013 (PR Newswire) - Outlook for 2013

For 2013, the company estimates results from continuing operations, before special items, as follows:

-- Revenue growth of between $0 \%$ and $1 \%$;

-- Earnings per diluted share to be between $\$ 4.35$ and $\$ 4.55$

-- Cash provided by operations to approximate $\$ 1$ billion

-- Capital expenditures to approximate $\$ 250$ million

"In 2013 our focus will continue to be driving operational excellence and restoring growth," said Mr. Rusckowski. "We will build on the positive momentum of our 2012 Invigorate performance in 2013. We expect results from our efforts to restore growth to gradually build throughout 2013, and anticipate continued revenue softness in the first half, with improvement thereafter."

\section{Example 2: Valassis (VCI) Announces FY10 Guidance; Sees EPS of \$2.48}

9 December 2009 (StreetInsider.com) - Valassis (NYSE: VCI) today provided financial guidance for fullyear 2010, expecting adjusted EBITDA of approximately $\$ 280$ million. In 2010, we expect capital expenditures to be $\$ 25$ million, resulting in expected diluted cash earnings per share (EPS) of \$2.48. Management believes that adjusted EBITDA and diluted cash EPS are the most relevant performance measurement criteria for our business.

\section{Example 3: United Natural Foods, Inc. Updates Fiscal 2011 Guidance to Reflect Completion of Common Stock Offering}

13 October 2010 (PR Newswire) - United Natural Foods, Inc. (Nasdaq: UNFI) (the "Company") today announced it is updating its 2011 fiscal year earnings per diluted share guidance to reflect the common stock offering completed by the Company on October 6, 2010. The Company issued 4,427,500 new shares (including shares issued to cover the underwriters' overallotment option), and the net proceeds of approximately $\$ 138.4$ million were used to repay a portion of the Company's outstanding borrowings under its revolving credit facility.

Update to Fiscal 2011 Guidance

For fiscal 2011, ending July 30, 2011, the Company expects earnings per diluted share in the range of approximately $\$ 1.62$ to $\$ 1.71$ per share, an increase of approximately $3.2 \%$ to $8.9 \%$ over fiscal 2010 , reflecting the increased number of shares, partially offset by a reduction in interest expense. The Company had previously provided guidance on earnings per diluted share in the range of approximately $\$ 1.74$ to $\$ 1.83$ per share on a lower share base.

In addition, the Company is confirming its fiscal 2011 guidance for net sales in the range of approximately $\$ 4.35$ to $\$ 4.45$ billion, an increase of approximately $15.8 \%$ to $18.4 \%$ over fiscal 2010 . Capital expenditures continue to be expected in the range of approximately $1 \%$ of revenues, or approximately $\$ 42$ million to $\$ 45$ million during fiscal 2011. 
Example 4: Scripts related to capex guidance during earnings conference calls

\begin{tabular}{|c|c|c|}
\hline Company name & $\begin{array}{c}\text { Earnings } \\
\text { conference } \\
\text { call date }\end{array}$ & Text excerpted from the call transcript \\
\hline Swift Energy Co. & $2 / 27 / 2014$ & $\begin{array}{l}\text { Our } 2014 \text { capital budget of } \$ 300 \text { million to } \$ 350 \text { million will be } \\
\text { flexible adjusted based on the timing of transactions and the } \\
\text { marketplace fundamentals. }\end{array}$ \\
\hline Gen-Probe Inc. & $2 / 15 / 2011$ & $\begin{array}{l}\text { And we forecast capital expenditures of between } \$ 45 \text { million and } \\
\$ 55 \text { million in } 2011 \text {, an increase compared to last year, mainly } \\
\text { related to the build out of our European manufacturing and } \\
\text { distribution capabilities. }\end{array}$ \\
\hline $\begin{array}{l}\text { Brocade } \\
\text { Communications } \\
\text { Systems, Inc. }\end{array}$ & $11 / 20 / 2008$ & $\begin{array}{l}\text { We expect capital expenditures for FY ' } 09 \text { to be in the } \$ 48 \text { million } \\
\text { to } \$ 64 \text { million range, plus expenditures for the new campus of } \\
\text { approximately } \$ 100 \text { million. }\end{array}$ \\
\hline Donaldson Co Inc. & $9 / 13 / 2011$ & $\begin{array}{l}\text { Still looking to invest about } \$ 100 \text { million this year in capital } \\
\text { projects. We're continuing our strategic growth plans. Part of that } \\
\text { is going to be for capacity expansion, part of it's going to be } \\
\text { tooling for new products, some distribution, and then some } \\
\text { maintenance CapEx. }\end{array}$ \\
\hline Unisys Corp. & $1 / 29 / 2013$ & $\begin{array}{l}\text { As I did say in my comments, we anticipate } 2013 \text { CapEx in the } \\
\$ 150 \text { million to } \$ 175 \text { million range. Our capital expenditures are } \\
\text { in three areas, largest being the amount that supports our } \\
\text { outsourcing business followed by investments in marketable } \\
\text { software and the last of the internal infrastructure capital expense. }\end{array}$ \\
\hline $\begin{array}{l}\text { Peet's Coffee \& Tea } \\
\text { Inc. }\end{array}$ & $2 / 12 / 2009$ & $\begin{array}{l}\text { TOM CAWLEY: -- so we'll talk about } \$ 10 \text { million of CapEx. So } \\
\text { just to give you a breakout of where it is, the new stores will } \\
\text { consume circa } \$ 5 \text { million. We are going to do some remodels, } \\
\text { including our flagship first store that we're are going to be } \\
\text { remodeling. It's going to be closing in a week -- to start } \\
\text { remodeling at the Vine street store in Berkeley, and we'll spend } \\
\text { about } \$ 1.5 \text { million on remodels for the year. We spend close to } \\
\$ 2 \text { million on just regular stores. Just things that we're doing all } \\
\text { of the time. IT is a lot of spending this year. We will spend about } \\
\$ 4 \text { million on IT. And our specialty businesses in total just aren't } \\
-- \text { they use maybe a } \$ 1 \text { million total in capital. So there's not a lot } \\
\text { for grocery food service. And then we'll spend -- I said -- a couple } \\
\text { million in the plant. That should add to about } \$ 16 \text { million. }\end{array}$ \\
\hline $\begin{array}{l}\text { Jetblue Airways } \\
\text { Corp. }\end{array}$ & $3 / 10 / 2009$ & $\begin{array}{l}\text { When you look at aircraft CapEx, a number that looks like } \$ 315 \\
\text { million in } 2009 \text {, as you take a look at the bar graph here from } \\
2005 \text { to } 2008 \text {, it will give you a feel for what we're out there in } \\
\text { the marketplace from the standpoint of our capital expenditures. } \\
\text { Earlier this year, we mentioned that in addition to the } \$ 315 \\
\text { million in aircraft capital expenditures, another } \$ 185 \text { million in } \\
\text { CapEx for a total of } \$ 500 \text { million that we're looking at in the } \\
\text { course of } 2009 \text {. }\end{array}$ \\
\hline Transocean Ltd. & $2 / 24 / 2011$ & $\begin{array}{l}\text { Capital expenditures for } 2011 \text { are projected to be } \$ 1.1 \text { billion with } \\
\text { about } \$ 450 \text { million relating to newbuild construction costs and } \\
\text { associated capitalized interests, and the remaining } \$ 650 \text { million } \\
\text { for expenditures on the existing fleet. }\end{array}$ \\
\hline
\end{tabular}




\begin{tabular}{|c|c|c|}
\hline $\begin{array}{l}\text { Cameron } \\
\text { International Corp. }\end{array}$ & $1 / 31 / 2013$ & $\begin{array}{l}\text { BRAD HANDLER: Okay, thanks. Unrelated follow up then, } \\
\text { could you give us a little more color on your CapEx in '13? How } \\
\text { it's directed, what are you addressing in that } \$ 500 \text { million? } \\
\text { CHUCK SLEDGE: A couple things, we need to do some capacity } \\
\text { expansions in V\&M. We're pretty much at capacity there, so we } \\
\text { need to expand there, so we're going to do that. The majority of } \\
\text { the CapEx, though, we've got to continue the drilling investment. } \\
\text { Our customers expect it. We expect it. It needs to continue to } \\
\text { occur. So, you're going to have north of } \$ 100 \text { million still going } \\
\text { into drilling. Subsea, we don't need any roofline, but there's } \\
\text { opportunities for life of field, and there's opportunities for rental } \\
\text { tools that we need to invest in. Then, we have our business } \\
\text { system, which obviously, we're continuing the implementation } \\
\text { of, so that has some CapEx implications. }\end{array}$ \\
\hline
\end{tabular}




\title{
Appendix C: Examples of analyst feedback regarding capex guidance
}

\section{Example 1: Analysts Question Marathon Spending Plans -- Market Talk}

\author{
4 December 2015 Dow Jones Institutional News
}

Refiner Marathon Petroleum closed its deal to buy Markwest Energy Partners and announced ambitious capital spending and growth plans. So why are investors punishing it? Marathon shares are down 7.5\% since Wednesday, and shares of its partnership, MPLX, have also tumbled. The problem is that investors are skeptical that the company can make good on its spending plans in the face of a collapse in the MLP sector--once a reliable way to raise cash. Laundry lists of new projects now look more like liabilities than growth opportunities: The question is "So how you gonna finance THAT?" says Wolfe research analyst Paul Sankey. Tudor Pickering Holt analysts say many investors are having trouble looking past low commodity prices. "Within the current oil and gas environment increasing capex levels in many investors' minds is like the flu -- nobody wants it."

\section{Example 2: Intel's future may be as an expensive factory; Commentary: Foundry business could offset shrinking PC market}

\section{January 2013 MarketWatch}

SAN FRANCISCO (MarketWatch) - Intel Corp. executives were probably not looking forward to Thursday's conference call with Wall Street, after the company's sharp drop in fourth quarter profits and disappointing forecast put a downspin on its stock. But the tone among analysts might have been even worse than what they imagined. As Wall Street looked at Intel's 2013 plans for capital spending, which includes the costly retooling of its world class chip-making plants, analysts questioned the company's level of spending, amid fears that Intel won't make enough chips to fill up the factories. Intel said it plans capital expenditures at about $\$ 13$ billion this year.

Part of its hefty spending will include start-up costs for new fabrication facilities, or fabs, that will specialize in new manufacturing process that makes the transistors ever thinner and more powerful. But several analysts continued to ask about Intel's news last May that it would manufacture chips for other companies, which Chief Executive Paul Otellini reiterated would only be on a speciality basis, and for companies that are not in competing markets with Intel.

Such a move into what is commonly called the "foundry" business that is currently dominated by players such as Taiwan's TSMC and Samsung would offer the advantage of keeping Intel's plants running, and likely give the company an edge in higher-end products, given its well-known expertise in high-volume chip making.

But the foundry business does not offer anywhere near the same kinds of margins as selling internally designed chip products. While Intel is dipping its toes in these waters, the company seemed to take pains on Thursday to point out that they still plan to charge high dollar for these services.

On a conference call, CFO Stacy Smith said "around our expectations about return, I mean it's pretty simple. To the extent we engage with these foundry customers, we want to make money at it. We want to get paid in terms of margin and we want to get a return on our invested capital commensurate with our technology leadership."

In other words, don't look for Intel to offer cut-rate pricing on making commodity level chips. But if the PC business does not recover soon, the company may find itself more flexible on this point.

Wall Street is nervous about Intel's 2013 plans for capital spending, which includes the costly retooling of its world class chip-making plants, because they are afraid Intel won't have enough demand to fill up its factories. 
Example 3: Analysts' questions regarding capex guidance during earnings conference calls

\begin{tabular}{|c|c|c|}
\hline Company name & $\begin{array}{c}\text { Earnings } \\
\text { conference } \\
\text { call date }\end{array}$ & Text excerpted from the call transcript \\
\hline $\begin{array}{l}\text { Honeywell } \\
\text { International Inc. }\end{array}$ & $3 / 6 / 2013$ & $\begin{array}{l}\text { Okay, great. And then, Dave, you -- Dave and Dave, you both } \\
\text { made a case today of how successful the execution has been in } \\
\text { capital deployed, certainly CapEx investments, M\&A } \\
\text { investments, et cetera. At what point do we start seeing you get } \\
\text { even more aggressive on capital deployment or looking to } \\
\text { provide more financial leverage or looking to push even harder } \\
\text { and faster, given how successful, frankly, the track record has } \\
\text { been to this point? Why not get more aggressive even sooner? Is } \\
\text { it execution risk you guys are thinking about? I mean, you talked } \\
\text { about physical capacity to do more. }\end{array}$ \\
\hline Cambrex Corp. & $2 / 11 / 2010$ & $\begin{array}{l}\text { Yes, thank you very much. Kind of switching gears a little bit. } \\
\text { You went through an investment phase where you expanded } \\
\text { production and upgraded facilities in all three of your major } \\
\text { product sites. Your guidance for CapEx for } 2010 \text { is } \$ 12 \text { to } \$ 50 \\
\text { million versus G\&A of } 23 \text { or so. It sounds to me like you're } \\
\text { getting down to almost maintenance CapEx in } 2010 \text {. How long } \\
\text { can this level of investment go on? Do you expect to be, do you } \\
\text { have to ramp up your CapEx at some time in the future closer to } \\
\text { G\&A number? }\end{array}$ \\
\hline Schlumberger NV. & $1 / 17 / 2014$ & $\begin{array}{l}\text { And what is it in your business that gives you confidence that you } \\
\text { can take CapEx down while your revenue is increasing? I mean } \\
\text { that is something that no other company has historically been able } \\
\text { to do. }\end{array}$ \\
\hline Foot Locker Inc. & $3 / 8 / 2013$ & $\begin{array}{l}\text { You're obviously increasing your CapEx budget this year. But } \\
\text { you're sitting on about } \$ 1 \text { billion of cash, no debt if you exclude } \\
\text { operating leases, about } 20 \% \text { of your market cap. Is there any } \\
\text { desire to maybe get more aggressive there? }\end{array}$ \\
\hline United Rentals Inc. & $4 / 14 / 2013$ & $\begin{array}{l}\text { Hi. Good morning, guys. Just wanted to get a sense for how } \\
\text { committed you are to holding the line on this } \$ 1 \text { billion net CapEx } \\
\text { number. What is sort of the optimal mix here? If you can get } \\
68.5 \% \text { utilization and keep the } 4.5 \% \text { rate, would that trigger a } \\
\text { higher CapEx number? Or how are you thinking about the } \\
\text { balance there? Because your } 68 \% \text { number would actually be } \\
\text { above what you've done the last couple of years. }\end{array}$ \\
\hline Plexus Corp. & $11 / 7 / 2012$ & $\begin{array}{l}\text { Thanks for that. And then I'm just curious, if you think of the } \\
20105 \% \text { model which address have targeted, historically, does } \\
\text { that still remain intact beyond fiscal '13, and then how do you } \\
\text { think about, a, potentially having to restructure some of the } \\
\text { manufacturing capacity; and, secondly, maybe curtailing the } \\
\text { CapEx, especially in Neenah, Wisconsin given the revenue } \\
\text { attrition over there. }\end{array}$ \\
\hline Corning Inc. & $7 / 27 / 2011$ & $\begin{array}{l}\text { Jim, the glass volumes now are expected to grow only } 6 \% \text { this } \\
\text { year, versus your original expectations of } 17 \% \text { at the beginning } \\
\text { of the year, on a sort of apples-to-apples basis. So, given this, is } \\
\text { there any consideration of cutting LCD-related CapEx? And I sort }\end{array}$ \\
\hline
\end{tabular}




\begin{tabular}{|l|l|}
\hline & $\begin{array}{l}\text { of mean in aggregate for 2011 and '12. You were talking about } \\
\text { actually increasing CapEx, given some of this production } \\
\text { capacity that you're converting over to Gorilla, which is leading } \\
\text { to incremental Taichung expansion. But on the other hand, the } \\
\text { end markets are a lot slower than you anticipated at the beginning } \\
\text { of the year. So, I'm just trying to understand -- is the China LCD } \\
\text { build still as strategic to you as you thought before? And -- even } \\
\text { though you're spreading it across a longer period of time. And } \\
\text { what is, specifically, the need to increase the Taichung facility, } \\
\text { especially if you're going to get some offset from thinner glass? } \\
\text { Thank you. }\end{array}$ \\
\hline
\end{tabular}




\section{Figure 1. Timeline}

This figure depicts how we identify the timing of our main test variables to measure capex guidance issuance $(C P X G D)$, analyst capex guidance feedback (FEEDBACK), capex guidance revision $\left(C P X G D \_R E V\right)$, and capex forecast error $\left(C P X G D_{-} E R R\right)$. Specifically, we identify the initial management capex guidance issued during the first fiscal quarter. We identify the earliest analyst capex forecast issued in the period between one day after the management capex guidance date and one day before the subsequent quarterly earnings announcement date or the management capex guidance revision date, whichever is earlier.

\section{Initial capex guidance issued}

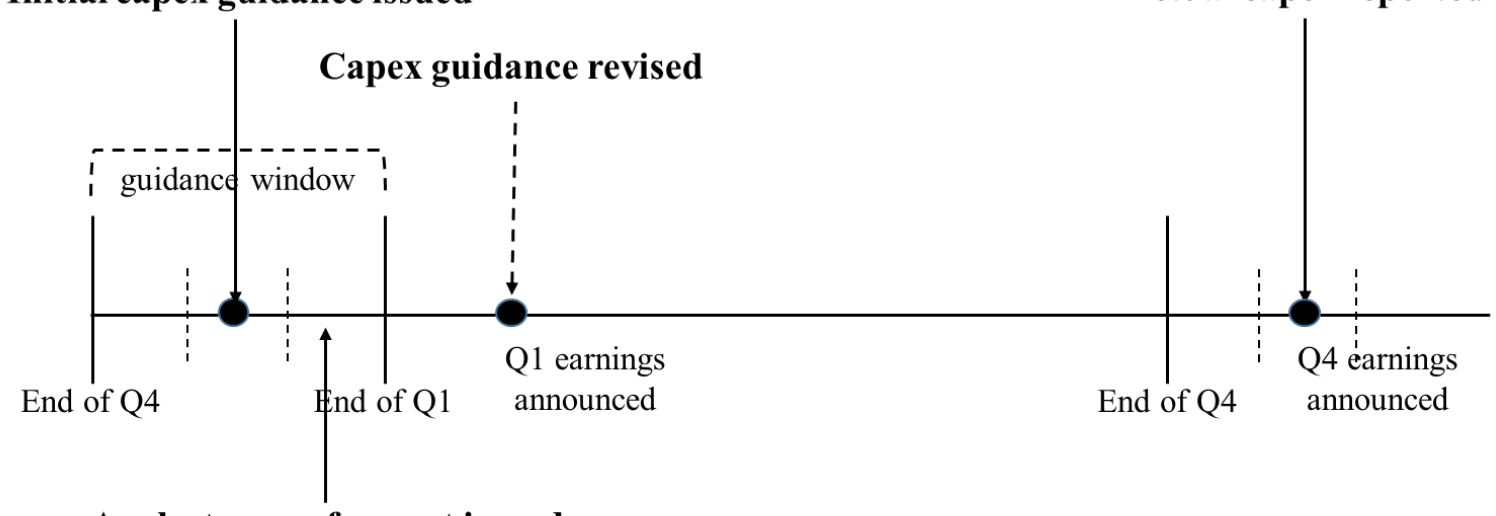

\section{Analyst capex forecast issued}

$C P X G D=$ Indicator variable equal to one if firm issues capex guidance for target year $t$ during the first quarter of fiscal year $t$, and zero otherwise;

FEEDBACK = Analyst median capex forecast issued after managerial capex guidance minus managerial capex guidance divided by beginning of year net property, plant, and equipment, multiplied by 100 ;

$C P X G D \_R E V=$ Updated managerial capex guidance subsequent to post-guidance analysts' capex forecasts minus initial managerial capex guidance divided by beginning of year net property, plant and equipment, multiplied by 100 ;

$C P X G D_{-} E R R=$ Actual capital expenditure minus initial capex guidance divided by beginning of year net property, plant and equipment, multiplied by 100 . 


\section{Table 1. Sample distributions}

This table presents sample distributions. Panel A presents proportions of capex guidance and earnings guidance in our study sample. Panel B reports distributions of capex guidance and earnings guidance by year. Panel $\mathrm{C}$ shows distributions of capex guidance and earnings guidance by industry. Panel D presents the number of breaks in capex guidance after disclosing capex guidance for at least one year. Panel E presents the number of breaks in earnings guidance after disclosing earnings guidance for at least one year. See Appendix A for variable definitions. ***, **, * indicate statistical significance at the $1 \%, 5 \%$, and $10 \%$ levels for two-tailed tests, respectively.

\section{Panel A. Proportions of capex guidance and earnings guidance}

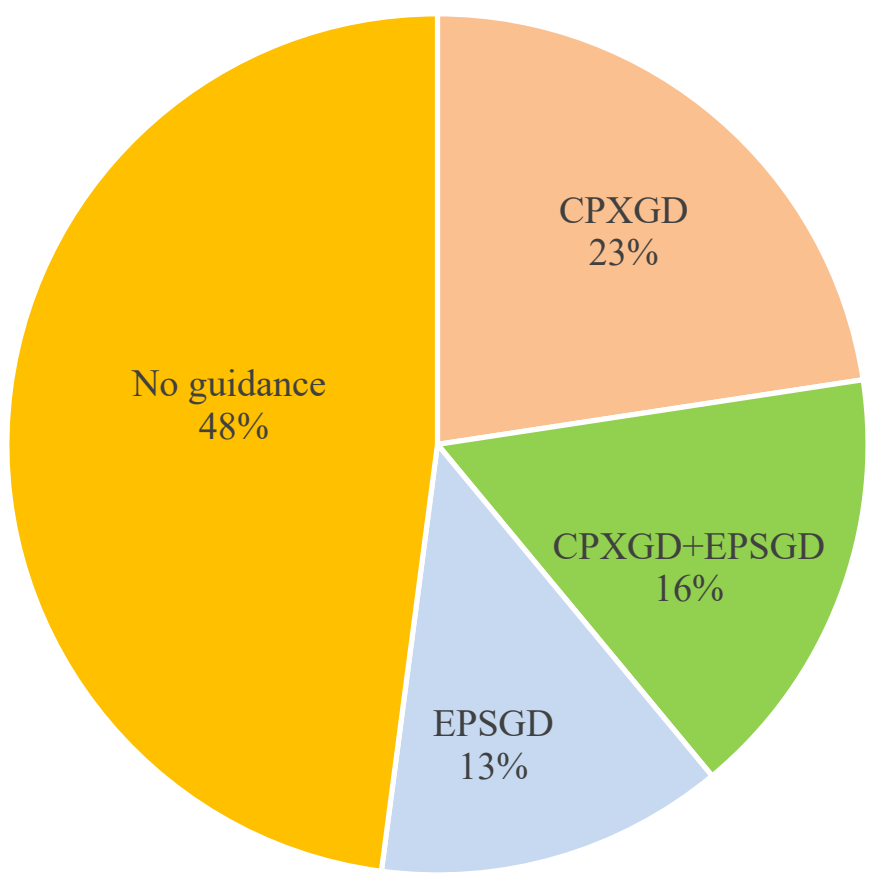

Panel B. Distributions of capex guidance and earnings guidance by year

\begin{tabular}{|c|c|c|c|c|c|c|}
\hline \multirow{2}{*}{ Year } & \multirow{2}{*}{ Total } & \multicolumn{2}{|c|}{ (1) } & \multicolumn{2}{|c|}{ (2) } & $(1)-(2)$ \\
\hline & & $C P X G D_{t}=1$ & CPXGD (\%) & $E P S G D_{t}=1$ & EPSGD (\%) & $(\% \mathrm{p})$ \\
\hline 2009 & 842 & 324 & 38.5 & 234 & 27.8 & $10.7 * * *$ \\
\hline 2010 & 976 & 381 & 39.0 & 284 & 29.1 & $9.9 * * *$ \\
\hline 2011 & 1,053 & 418 & 39.7 & 312 & 29.6 & $10.1 * * *$ \\
\hline 2012 & 1,185 & 486 & 41.0 & 365 & 30.8 & $10.2 * * *$ \\
\hline 2013 & 1,212 & 475 & 39.2 & 360 & 29.7 & $9.5^{* * *}$ \\
\hline 2014 & 1,162 & 423 & 36.4 & 341 & 29.3 & $7.1 * * *$ \\
\hline Total & 6,430 & 2,507 & 39.0 & 1,896 & 29.5 & $9.5 * * *$ \\
\hline
\end{tabular}


Panel C. Distributions of capex guidance and earnings guidance by industry

\begin{tabular}{l|c|cc|cc|c}
\hline \multirow{1}{*}{ Industry } & \multirow{2}{*}{ Total } & \multicolumn{2}{c|}{$(1)$} & \multicolumn{2}{c|}{$(2)$} & $(1)-(2)$ \\
& & $C P X G D_{t}=1$ & $C P X G D(\%)$ & $E P S G D_{t}=1$ & EPSGD (\%) & (\%p) \\
\hline Chemicals & 282 & 129 & 45.7 & 100 & 35.5 & $10.3^{* * *}$ \\
Computers & 1,110 & 256 & 23.1 & 283 & 25.5 & -2.4 \\
Durable manufacturers & 1,679 & 595 & 35.4 & 599 & 35.7 & -0.2 \\
Extractive industries & 572 & 369 & 64.5 & 20 & 3.5 & $61.0^{* * *}$ \\
Food & 251 & 105 & 41.8 & 90 & 35.9 & $6.0^{* *}$ \\
Mining and construction & 139 & 45 & 32.4 & 0 & 0.0 & $32.4^{* * *}$ \\
Pharmaceuticals & 438 & 85 & 19.4 & 153 & 34.9 & $-15.5^{* * *}$ \\
Retail & 681 & 410 & 60.2 & 276 & 40.5 & $19.7^{* * *}$ \\
Services & 780 & 273 & 35.0 & 261 & 33.5 & 1.5 \\
Textiles and Printing & 222 & 129 & 58.1 & 81 & 36.5 & $21.6^{* * *}$ \\
Transportation & 276 & 111 & 40.2 & 33 & 12.0 & $28.3^{* * *}$ \\
\hline \multicolumn{1}{c}{ Total } & 6,430 & 2,507 & 39.0 & 1,896 & 29.5 & $9.5^{* * *}$ \\
\hline
\end{tabular}

Panel D. Number of breaks in capex guidance after capex guidance disclosed at least one year

\begin{tabular}{c|cc|cc|cc|cc}
\hline \multirow{2}{*}{$\begin{array}{c}\text { Number of } \\
\text { breaks }\end{array}$} & \multicolumn{2}{|c|}{ Total firms } & \multicolumn{2}{c|}{\begin{tabular}{c}
\multicolumn{2}{c|}{ Firms with 6 data } \\
years
\end{tabular}} & \multicolumn{2}{c|}{ Firms with 5 data } & \multicolumn{2}{c}{$\begin{array}{c}\text { Firms with 4 data } \\
\text { years }\end{array}$} \\
\cline { 2 - 9 } & $\mathrm{N}$ & $\%$ & $\mathrm{~N}$ & $\%$ & $\mathrm{~N}$ & $\%$ & $\mathrm{~N}$ & $\%$ \\
\hline 0 & 489 & 55.4 & 109 & 59.9 & 86 & 45.7 & 51 & 32.5 \\
1 & 321 & 36.4 & 63 & 34.6 & 79 & 42.0 & 77 & 49.0 \\
2 & 69 & 7.8 & 9 & 4.9 & 22 & 11.7 & 27 & 17.2 \\
3 & 4 & 0.5 & 1 & 0.5 & 1 & 0.5 & 2 & 1.3 \\
Total & 883 & 100.0 & 182 & 100.0 & 188 & 100.0 & 157 & 100.0 \\
\hline
\end{tabular}

Panel E. Number of breaks in earnings guidance after earnings guidance disclosed at least one year

\begin{tabular}{c|cc|cc|cc|cc}
\hline \multirow{2}{*}{$\begin{array}{c}\text { Number of } \\
\text { breaks }\end{array}$} & \multicolumn{2}{|c|}{ Total firms } & \multicolumn{2}{c|}{$\begin{array}{c}\text { Firms with 6 data } \\
\text { years }\end{array}$} & \multicolumn{2}{c|}{$\begin{array}{c}\text { Firms with 5 data } \\
\text { years }\end{array}$} & \multicolumn{2}{c}{$\begin{array}{c}\text { Firms with 4 data } \\
\text { years }\end{array}$} \\
\cline { 2 - 9 } & $\mathrm{N}$ & $\%$ & $\mathrm{~N}$ & $\%$ & $\mathrm{~N}$ & $\%$ & $\mathrm{~N}$ & $\%$ \\
\hline 0 & 429 & 71.6 & 90 & 62.9 & 82 & 66.1 & 65 & 66.3 \\
1 & 155 & 25.9 & 44 & 30.8 & 38 & 30.6 & 32 & 32.7 \\
2 & 15 & 2.5 & 9 & 6.3 & 4 & 3.2 & 1 & 1.0 \\
3 & 0 & 0.0 & 0 & 0.0 & 0 & 0.0 & 0 & 0.0 \\
Total & 599 & 100.0 & 143 & 100.0 & 124 & 100.0 & 98 & 100.0 \\
\hline
\end{tabular}




\section{Table 2. Summary statistics}

This table presents summary statistics for study variables for our samples of capex guidance and nonguidance firm-years. All continuous independent variables are winsorized at the 1\% and $99 \%$ levels. All variables have $t-1$ time subscripts except where indicated. See Appendix A for variable definitions.

\begin{tabular}{|c|c|c|c|c|}
\hline \multirow[t]{2}{*}{ Variables } & \multicolumn{2}{|c|}{$\begin{array}{c}\text { (1) } C P X G D_{t}=1 \\
(\mathrm{~N}=2,507)\end{array}$} & \multicolumn{2}{|c|}{$\begin{array}{c}\text { (2) } C P X G D_{t}=0 \\
(\mathrm{~N}=3,923)\end{array}$} \\
\hline & Mean & Median & Mean & Median \\
\hline$I N V E F F_{t}$ & -12.802 & -11.136 & -17.358 & -12.868 \\
\hline$E P S G D$ & 0.418 & 0.000 & 0.218 & 0.000 \\
\hline$C P X G D$ & 0.874 & 1.000 & 0.157 & 0.000 \\
\hline INSTOWN & 0.604 & 0.763 & 0.530 & 0.635 \\
\hline$A N A L Y S T$ & 1.487 & 1.386 & 1.277 & 1.099 \\
\hline$F R Q$ & -0.042 & -0.028 & -0.061 & -0.037 \\
\hline$L E V$ & 0.239 & 0.228 & 0.194 & 0.155 \\
\hline FREECF & 0.363 & 0.107 & 0.825 & 0.137 \\
\hline$S T D C P X$ & 9.809 & 5.876 & 16.831 & 8.297 \\
\hline STDRET & 0.129 & 0.118 & 0.134 & 0.124 \\
\hline CAPINT & 0.342 & 0.263 & 0.223 & 0.131 \\
\hline$R O A$ & 0.052 & 0.057 & 0.025 & 0.051 \\
\hline$M T B$ & 2.695 & 2.088 & 2.813 & 2.127 \\
\hline RISKIND & 0.296 & 0.000 & 0.429 & 0.000 \\
\hline DISSEM_MEDIA & 0.122 & 0.000 & 0.004 & 0.000 \\
\hline
\end{tabular}

Note: Mean and median differences are statistically significant for all the variables except $M T B$. 


\section{Table 3. Tests of H1 - Analyst feedback and capex guidance forecast errors and revisions}

This table presents regression tests for associations between analyst feedback $\left(F E E D B A C K_{t}\right)$, and managerial capex adjustments in Column (1) and guidance revisions in Column (2). See Appendix A for variable definitions. Standard errors are clustered by firm. ***,**,* indicate statistical significance at the $1 \%, 5 \%$, and $10 \%$ levels for two-tailed tests, respectively. One-tailed tests are used only when a sign is predicted.

\begin{tabular}{|c|c|c|c|c|c|}
\hline \multirow[b]{2}{*}{ Variables } & \multirow[b]{2}{*}{ Pred. } & \multicolumn{2}{|c|}{$\begin{array}{l}\text { (1) Actual capex adjustment } \\
\text { Dep. Var. }=C P X G D_{-} E R R_{t}\end{array}$} & \multicolumn{2}{|c|}{$\begin{array}{l}\text { (2) Capex guidance revision } \\
\text { Dep. Var. }=C P X G D_{-} R E V_{t}\end{array}$} \\
\hline & & Coeff. & t-stat. & Coeff. & t-stat \\
\hline INTERCEPT & & 0.819 & 0.38 & -0.355 & -0.62 \\
\hline$F E E D B A C K_{t}$ & + & 0.576 & $5.33 * * *$ & 0.057 & $2.89 * * *$ \\
\hline INDCPXGROWTH $H_{t}$ & & 0.023 & $2.13^{* *}$ & 0.001 & 0.43 \\
\hline$C P X G R O W T H_{-} Q 1_{t}$ & & 0.017 & $6.40 * * *$ & 0.002 & $3.02 * * *$ \\
\hline$C A R_{-} 5 D A Y_{t}$ & & 0.243 & 1.36 & 0.074 & 1.10 \\
\hline Fixed Effects & & \multicolumn{2}{|c|}{ Industry, Year, Industry*Year } & \multicolumn{2}{|c|}{ Industry, Year, Industry*Year } \\
\hline$N$ & & \multicolumn{2}{|c|}{2,117} & \multicolumn{2}{|c|}{1,708} \\
\hline $\mathrm{R}^{2}$ & & \multicolumn{2}{|c|}{0.253} & \multicolumn{2}{|c|}{0.117} \\
\hline
\end{tabular}




\section{Table 4. Tests of $\mathrm{H2}$ - Analyst feedback and investment efficiency changes}

This table tests whether analyst feedback to managerial capex guidance is associated with enhanced capital investment efficiency. Specifically, this table tests for the effect of analyst feedback (FEEDBACK_DEV $\left.V_{t}\right)$ on differences in investment efficiency between actual capex and capex guidance (INVEFF_DIFF_ACTUAL_MF $\left.F_{t}\right)$ after controlling for the effect of analyst capex forecast revisions on investment efficiency changes in the absence of capex guidance (PSEUDOFEEDBACK_DEV $t$ ). All variables have $t-1$ time subscripts except where indicated. See Appendix A for variable definitions. Standard errors are clustered by firm. $* * * * *, *$ indicate statistical significance at the $1 \%, 5 \%$, and $10 \%$ levels for two-tailed tests, respectively. One-tailed tests are used only when a sign is predicted.

\begin{tabular}{|c|c|c|c|}
\hline \multirow[b]{2}{*}{ Variables } & \multirow[b]{2}{*}{ Pred. } & \multicolumn{2}{|c|}{$\begin{array}{c}\text { Dep. Var. } \\
=I N V E F F_{-} D I F F_{-} A C T U A L_{-} M F_{t}\end{array}$} \\
\hline & & Coeff. & t-stat. \\
\hline INTERCEPT & & -1.575 & -1.53 \\
\hline$F E E D B A C K_{-} D E V_{t}$ & + & 0.510 & $4.74 * * *$ \\
\hline PSEUDOFEEDBACK_DEV $V_{t}$ & + & 0.108 & $1.45^{*}$ \\
\hline CHGEPSGD & & -0.021 & -0.03 \\
\hline CHGEPSGD*CHGEPSGACC & & 12.616 & 1.00 \\
\hline CHGINSTOWN & & -3.965 & -1.60 \\
\hline CHGANALYST & & -0.289 & -0.99 \\
\hline CHGFRQ & & -3.342 & -0.75 \\
\hline CHGLEV & & -1.269 & -0.33 \\
\hline CHGFREECF & & -0.318 & -1.27 \\
\hline$C H G S T D C P X$ & & 0.005 & 0.26 \\
\hline CHGTOBINQ & & 0.086 & 0.85 \\
\hline $\mathrm{CHGCF}_{t}$ & & 0.022 & 0.08 \\
\hline Fixed Effects & & \multicolumn{2}{|c|}{ Industry, Year, Industry*Year } \\
\hline Difference test & & \multirow{2}{*}{\multicolumn{2}{|c|}{$0.402 * * *$}} \\
\hline FEEDBACK_DEV $V_{t}-P S E U D O F E E D B A C K_{-} D E V_{t}$ & + & & \\
\hline $\mathrm{N}$ & & \multicolumn{2}{|c|}{4,796} \\
\hline $\mathrm{R}^{2}$ & & \multicolumn{2}{|c|}{0.053} \\
\hline
\end{tabular}


Table 5. Tests of $\mathrm{H3}$ - Capex adjustments and firm financial performance

This table presents regression results for associations between the capex adjustments or capex guidance revisions predicted by analyst feedback to capex guidance and future firm performance. Panel A reports tests for association between the predicted capex adjustments (PredCPXGD_ERR $R_{t}$ ), and the future return on assets $\left(R O A_{t+1}\right)$ in Column (1) and the future operating cash flow $\left(C F O_{t+1}\right)$ in Column (2). Panel B reports tests for associations between the predicted capex guidance revision (PredCPXGD_REV $V_{t}$ ), and the future return on assets $\left(R O A_{t+1}\right)$ in Column (1) and the future operating cash flow $\left(C F O_{t+1}\right)$ in Column (2). Standard errors are clustered by firm. $* * *, * *, *$ indicate statistical significance at the $1 \%, 5 \%$, and $10 \%$ levels for two-tailed tests, respectively. One-tailed tests are used only when a sign is predicted.

Panel A. PredCPXGD_ERR

\begin{tabular}{|c|c|c|c|c|c|}
\hline \multirow[b]{2}{*}{ Variables } & \multirow[b]{2}{*}{ Pred. } & \multicolumn{2}{|c|}{$\begin{array}{l}\text { (1) Actual capex adjustment } \\
\text { Dep. Var. }=R O A_{t+1}\end{array}$} & \multicolumn{2}{|c|}{$\begin{array}{l}\text { (2) Capex guidance revision } \\
\text { Dep. Var. }=C F O_{t+1}\end{array}$} \\
\hline & & Coeff. & t-stat. & Coeff. & t-stat \\
\hline INTERCEPT & & -0.015 & -0.80 & 0.096 & $4.45^{* * *}$ \\
\hline PredCPXGD_ERR $R_{t}$ & + & 0.001 & $2.97 * * *$ & 0.000 & $1.73 * *$ \\
\hline$L O G M V_{t}$ & & 0.004 & $4.27 * * *$ & 0.000 & -0.84 \\
\hline$B T M_{t}$ & & -0.036 & $-6.13 * * *$ & 0.132 & $4.84 * * *$ \\
\hline$R O A_{t}$ & & 0.398 & $8.82 * * *$ & -0.022 & $-5.31 * * *$ \\
\hline $\mathrm{CFO}_{t}$ & & 0.239 & $6.46^{* * *}$ & 0.550 & $17.18 * * *$ \\
\hline Fixed Effects & & \multicolumn{2}{|c|}{ Industry, Year, Industry*Year } & \multicolumn{2}{|c|}{ Industry, Year, Industry*Year } \\
\hline$N$ & & \multicolumn{2}{|c|}{2,117} & \multicolumn{2}{|c|}{2,117} \\
\hline $\mathrm{R}^{2}$ & & \multicolumn{2}{|c|}{0.477} & \multicolumn{2}{|c|}{0.562} \\
\hline
\end{tabular}

Panel B. PredCPXGD_REV

\begin{tabular}{|c|c|c|c|c|c|}
\hline \multirow[b]{2}{*}{ Variables } & \multirow[b]{2}{*}{ Pred. } & \multicolumn{2}{|c|}{$\begin{array}{l}\text { (1) Actual capex adjustment } \\
\text { Dep. Var. }=R O A_{t+1}\end{array}$} & \multicolumn{2}{|c|}{$\begin{array}{l}\text { (2) Capex guidance revision } \\
\text { Dep. Var. }=C F O_{t+1}\end{array}$} \\
\hline & & Coeff. & t-stat. & Coeff. & t-stat \\
\hline INTERCEPT & & -0.001 & -0.07 & 0.102 & $4.00 * * *$ \\
\hline PredCPXGD_REV $V_{t}$ & + & 0.016 & $3.03 * * *$ & 0.010 & $2.48 * * *$ \\
\hline$L O G M V_{t}$ & & 0.005 & $4.20 * * *$ & 0.000 & -0.87 \\
\hline$B T M_{t}$ & & -0.039 & $-5.70 * * *$ & -0.023 & $-4.88 * * *$ \\
\hline$R O A_{t}$ & & 0.363 & $7.50^{* * *}$ & 0.137 & $4.34 * * *$ \\
\hline $\mathrm{CFO}_{t}$ & & 0.246 & $6.17 * * *$ & 0.532 & $15.27 * * *$ \\
\hline Fixed Effects & & \multicolumn{2}{|c|}{ Industry, Year, Industry*Year } & \multicolumn{2}{|c|}{ Industry, Year, Industry*Year } \\
\hline$N$ & & \multicolumn{2}{|c|}{1,708} & \multicolumn{2}{|c|}{1,708} \\
\hline $\mathrm{R}^{2}$ & & \multicolumn{2}{|c|}{0.458} & \multicolumn{2}{|c|}{0.558} \\
\hline
\end{tabular}


Table 6. Textual analyses of tone in analysts' questions regarding capex guidance during conference calls

This table presents the results using tone in analysts' questions on capex guidance during the conference calls as a proxy for analyst feedback to managers regarding their capex guidance. Panel A presents distributions of the number of analyst questions on capex guidance per conference call (QUEST_NUM), the number of analysts' negative tone questions on capex guidance per conference call (NEGTONEQUEST_NUM), an indicator variable for at least one analyst question on capex guidance during a conference call and zero otherwise (QUEST_D), an indicator variable for at least one analysts' negative tone question on capex guidance during a conference call and zero otherwise (NEGTONEQUEST_D). Panel $\mathrm{B}$ presents the association between analyst feedback deviation and the incidence of analysts' negative tone questions after controlling for other factors that influence analyst feedback deviation. Panel $\mathrm{C}$ tests for associations between the incidence of analysts' negative tone question (NEGTONEQUEST_ $D_{t}$ ) and absolute value of managerial capex adjustments in Column (1) and absolute value of guidance revisions in Column (2). Panel D tests for associations between incidence of analysts' negative tone questions (NEGTONEQUEST_D $D_{t}$ ) and absolute value of managerial capex adjustments conditional on guidance revisions. Panel $\mathrm{E}$ tests for the effect of the incidence of analysts' negative tone questions (NEGTONEQUEST_D $D_{t}$ ) on differences in investment efficiency between actual capex and capex guidance $\left(I N V E F F_{-} D I F F_{-} A C T U A L_{-} M F_{t}\right)$. All variables have $t-1$ time subscripts except where indicated. See Appendix A for variable definitions. Standard errors are clustered by firm. ***, **, * indicate statistical significance at the $1 \%, 5 \%$, and $10 \%$ levels for two-tailed tests, respectively. One-tailed tests are used only when a sign is predicted.

Panel A. Means $(\mathrm{N}=6,430)$

\begin{tabular}{l|ccc}
\hline & $\begin{array}{c}\text { (1) } C P X G D_{t}=1 \\
(\mathrm{~N}=2,507)\end{array}$ & $\begin{array}{c}\text { (2) } C P X G D_{t}=0 \\
(\mathrm{~N}=3,923)\end{array}$ & $(1)-(2)$ \\
\hline QUEST_NUM & 0.703 & 0.229 & $0.474^{* * *}$ \\
NEGTONEQUEST_NUM & 0.299 & 0.095 & $0.204^{* * * *}$ \\
QUEST_D & 0.391 & 0.153 & $0.238^{* * *}$ \\
NEGTONEQUEST_D & 0.212 & 0.073 & $0.139^{* * *}$ \\
\hline
\end{tabular}

Panel B. The relation between feedback deviation and incidence of analysts' negative tone questions

\begin{tabular}{|c|c|c|c|}
\hline \multirow[b]{2}{*}{ Variables } & \multirow[b]{2}{*}{ Pred. } & \multicolumn{2}{|c|}{ Dep. Var. $=F E E D B A C K_{-} D E V_{t}$} \\
\hline & & Coeff. & t-stat. \\
\hline INTERCEPT & & 3.131 & $3.13 * * *$ \\
\hline$N E G T O N E Q U E S T \_D_{t}$ & + & 0.442 & $1.68 * *$ \\
\hline$L O G M V$ & & -0.135 & -1.22 \\
\hline ANALYST & & -0.379 & -1.38 \\
\hline$M T B$ & & 0.003 & 0.10 \\
\hline CAPINT & & -4.421 & $-5.55 * * *$ \\
\hline$S T D C P X$ & & 0.023 & $2.00^{* *}$ \\
\hline$R A N G E C P X_{-} D_{t}$ & & 0.579 & $1.96^{*}$ \\
\hline Fixed Effects & & \multicolumn{2}{|c|}{ Industry, Year, Industry*Year } \\
\hline $\mathrm{N}$ & & \multicolumn{2}{|c|}{2,117} \\
\hline $\mathrm{R}^{2}$ & & \multicolumn{2}{|c|}{0.088} \\
\hline
\end{tabular}


Panel C. Incidence of analysts' negative tone questions and capex guidance forecast errors (revisions)

\begin{tabular}{|c|c|c|c|c|c|}
\hline \multirow[b]{2}{*}{ Variables } & \multirow[b]{2}{*}{ Pred. } & \multicolumn{2}{|c|}{$\begin{array}{l}\text { (1) Actual capex adjustment } \\
\text { Dep. Var. } \\
=A B S C P X G D_{-} E R R_{t}\end{array}$} & \multicolumn{2}{|c|}{$\begin{array}{l}\text { (2) Capex guidance revision } \\
\text { Dep. Var. } \\
=A B S C P X G D_{-} R E V_{t}\end{array}$} \\
\hline & & Coeff. & t-stat. & Coeff. & t-stat. \\
\hline INTERCEPT & & 3.502 & $1.79 *$ & 1.196 & $2.93 * * *$ \\
\hline NEGTONEQUEST_D $D_{t}$ & + & 0.060 & 0.16 & 0.350 & $2.35 * * *$ \\
\hline ABSINDCPXGROWTH $H_{t}$ & & 0.017 & 1.44 & 0.003 & 0.83 \\
\hline ABSCPXGROWTH_Q $1_{t}$ & & 0.011 & $4.4 * * *$ & 0.001 & $1.85^{*}$ \\
\hline$C A R_{-} 5 D A Y_{t}$ & & 0.552 & $1.82 *$ & 0.096 & 1.07 \\
\hline Fixed Effects & & \multicolumn{2}{|c|}{$\begin{array}{l}\text { Industry, Year, } \\
\text { Industry*Year }\end{array}$} & \multicolumn{2}{|c|}{$\begin{array}{l}\text { Industry, Year, } \\
\text { Industry*Year }\end{array}$} \\
\hline$N$ & & \multicolumn{2}{|c|}{2,117} & \multicolumn{2}{|c|}{1,708} \\
\hline $\mathrm{R}^{2}$ & & \multicolumn{2}{|c|}{0.107} & \multicolumn{2}{|c|}{0.065} \\
\hline
\end{tabular}

Panel D. Incidence of analysts' negative tone questions and capex guidance forecast errors conditional on revisions

\begin{tabular}{|c|c|c|c|}
\hline \multirow[b]{2}{*}{ Variables } & \multirow[b]{2}{*}{ Pred. } & \multicolumn{2}{|c|}{$\begin{array}{c}\text { Actual capex adjustment } \\
\text { Dep. Var. }=A B S C P X G D_{-} E R R_{t}\end{array}$} \\
\hline & & Coeff. & t-stat. \\
\hline INTERCEPT & & 3.000 & 1.51 \\
\hline NEGTONEQUEST_D $D_{t}$ & & -0.520 & -1.22 \\
\hline$A B S C P X G D_{-} R E V_{-} D_{t}$ & & 0.698 & $1.90^{*}$ \\
\hline$N E G T O N E Q U E S T \_D_{t} * C P X G D_{-} R E V \_D_{t}$ & + & 1.523 & $1.94 * *$ \\
\hline$A B S I N D C P X G R O W T H_{t}$ & & 0.017 & 1.48 \\
\hline ABSCPXGROWTH_Q1 $1_{t}$ & & 0.011 & $4.43^{* * *}$ \\
\hline$C A R_{-} 5 D A Y_{t}$ & & 0.547 & $1.82 *$ \\
\hline Fixed Effects & & \multicolumn{2}{|c|}{ Industry, Year, Industry*Year } \\
\hline$N$ & & \multicolumn{2}{|c|}{2,117} \\
\hline $\mathrm{R}^{2}$ & & \multicolumn{2}{|c|}{0.113} \\
\hline
\end{tabular}

Panel E. Analysts' feedback measured by incidence of analysts' negative-tone questions and investment efficiency changes

\begin{tabular}{|c|c|c|c|}
\hline \multirow[b]{2}{*}{ Variables } & \multirow[b]{2}{*}{ Pred. } & \multicolumn{2}{|c|}{$\begin{array}{c}\text { (1) Dep. Var. } \\
=I N V E F F_{-} D I F F_{-} A C T U A L_{-} M F_{t}\end{array}$} \\
\hline & & Coeff. & t-stat. \\
\hline INTERCEPT & & -1.374 & -1.39 \\
\hline$N E G T O N E Q U E S T \_D_{t}$ & + & 0.775 & $1.48 *$ \\
\hline PSEUDONEGTONEQUEST_ $D_{t}$ & + & -0.520 & -0.57 \\
\hline CHGEPSGD & & -0.183 & -0.28 \\
\hline CHGEPSGD ${ }^{*} C H G E P S G A C C$ & & 11.348 & 0.97 \\
\hline CHGINSTOWN & & -3.907 & -1.56 \\
\hline CHGANALYST & & -0.209 & -0.67 \\
\hline CHGFRQ & & -2.659 & -0.59 \\
\hline
\end{tabular}




\begin{tabular}{l|cc} 
CHGLEV & -0.190 & -0.05 \\
CHGFREECF & -0.296 & -1.21 \\
CHGSTDCPX & 0.007 & 0.31 \\
CHGTOBINQ & 0.048 & 0.52 \\
CHGCF & -0.009 & -0.03 \\
Fixed Effects & Industry, Year, Industry*Year \\
\hline Difference test & \\
NEGTONEQUEST_D $t_{t}-$ & \\
PSEUDONEGTONEQUEST_D & \\
\hline $\mathrm{N}$ & & $1.295^{*}$ \\
$\mathrm{R}^{2}$ & \multicolumn{2}{|c}{4,796} \\
\hline
\end{tabular}


Table 7. Test of $\mathrm{H} 2$ using Biddle et al. (2009) conditional investment model

This table presents results using the Biddle et al. (2009) conditional investment model. Specifically, this table tests for the association between capital investment $\left(C A P X_{t}\right)$ and the direction of analysts' feedback (FEEDBACK_DEC $\left.C_{t}, F E E D B A C K_{-} Z E R O_{t}, F E E D B A C K_{-} I N C_{t}\right)$, conditioned by the likelihood of overinvestment (OVERFIRM). All variables have $t$ - 1 time subscripts except where indicated. See Appendix A for variable definitions. Standard errors are clustered by firm. $* * *, * *, *$ indicate statistical significance at the $1 \%, 5 \%$, and $10 \%$ levels for two-tailed tests, respectively. One-tailed tests are used only when a sign is predicted.

\begin{tabular}{|c|c|c|c|}
\hline \multirow[b]{2}{*}{ Variables } & \multirow[b]{2}{*}{ Pred. } & \multicolumn{2}{|c|}{ Dep. Var. $=C A P X_{t}$} \\
\hline & & Coeff. & t-stat. \\
\hline INTERCEPT & & 0.016 & 1.04 \\
\hline OVERFIRM & & 0.021 & 1.20 \\
\hline$F E E D B A C K_{-} D E C_{t}$ & & 0.018 & $2.55^{* *}$ \\
\hline FEEDBACK_ZERO ${ }_{t}$ & & -0.004 & -0.65 \\
\hline FEEDBACK_INC $C_{t}$ & + & 0.013 & $1.72 * *$ \\
\hline OVERFIRM ${ }^{*} F E E D B A C K_{-} D E C_{t}$ & - & -0.028 & $-2.35 * * *$ \\
\hline OVERFIRM $^{*} F E E D B A C K \_Z E R O_{t}$ & & 0.012 & 1.01 \\
\hline OVERFIRM*FEEDBACK_INC $C_{t}$ & & -0.015 & -1.23 \\
\hline$F R Q$ & & -0.110 & $-2.23 * *$ \\
\hline INSTOWN & & 0.014 & $1.97 * *$ \\
\hline ANALYST & & 0.004 & 1.15 \\
\hline OVERFIRM ${ }^{*} F R Q$ & & 0.123 & 1.65 \\
\hline OVERFIRM ${ }^{*} I N S T O W N$ & & -0.019 & $-1.72 *$ \\
\hline OVERFIRM ${ }^{*} A N A L Y S T$ & & -0.006 & -0.98 \\
\hline$L O G A T$ & & -0.001 & -1.05 \\
\hline$M T B$ & & 0.000 & $3.83^{* * *}$ \\
\hline$S T D C F O$ & & 0.034 & $2.20 * *$ \\
\hline STDSALES & & -0.009 & $-2.10 * *$ \\
\hline$S T D C A P X$ & & 0.000 & $2.36^{* *}$ \\
\hline ZSCORE & & -0.001 & -1.23 \\
\hline CAPINT & & 0.161 & $19.2^{* * *}$ \\
\hline KSTRUCTURE & & -0.051 & $-6.50 * * *$ \\
\hline INDKSTRUCTURE & & -0.029 & $-1.98 * *$ \\
\hline$C F O \_S$ & & 0.003 & $4.47^{* * *}$ \\
\hline$D I V$ & & -0.004 & $-2.35^{* *}$ \\
\hline FIRMAGE & & 0.000 & $-3.45 * * *$ \\
\hline OPCYCLE & & 0.001 & 0.97 \\
\hline LOSS & & -0.009 & $-4.58 * * *$ \\
\hline Fixed Effects & & \multicolumn{2}{|c|}{ Industry, Year, Industry*Year } \\
\hline \multicolumn{4}{|l|}{ Difference test } \\
\hline $\begin{array}{l}\text { FEEDBACK_DEC } C_{t}{ }^{+} \\
\text {OVERFIRM*FEEDBACK_DEC } C_{t}\end{array}$ & - & \multicolumn{2}{|c|}{$-0.010^{* *}$} \\
\hline $\mathrm{N}$ & & \multicolumn{2}{|c|}{5,668} \\
\hline $\mathrm{R}^{2}$ & & \multicolumn{2}{|c|}{0.593} \\
\hline
\end{tabular}




\title{
Online Addendum Containing Additional Analyses, Validity and Robustness Checks for:
}

\author{
"Managerial Learning from Analyst Feedback to Voluntary Capex Guidance, \\ Investment Efficiency and Firm Performance"
}

\author{
Jihun Bae, Gary C. Biddle, Chul W. Park
}

This online addendum (OA) contains additional analyses, validity and robustness checks extending and lending support to results presented in Bae J, Biddle GC, Park, CW (2020), Managerial Learning from Analyst Feedback to Voluntary Capex Guidance, Investment Efficiency and Firm Performance, Management Science. Definitions of variables used only in the addendum are below and other variable definitions, equations and citations are as provided in the main paper. ${ }^{1}$

\section{Addendum variable definitions}

\begin{tabular}{|c|c|c|}
\hline DIVERSE_HIGH & $=$ & $\begin{array}{l}\text { Indicator variable equal to one if the firm-year level of mean analyst } \\
\text { forecast diversity is greater than the sample median and zero otherwise. } \\
\text { We measure the individual analyst forecast diversity by the extent of } \\
\text { the analyst's coverage of sales, earnings and capex forecasts in the } \\
\text { prior year; }\end{array}$ \\
\hline$E X P \_H I G H$ & $=$ & $\begin{array}{l}\text { Indicator variable equal to one if the firm-year level of mean analyst } \\
\text { forecast experience is greater than the sample median and zero } \\
\text { otherwise. We measure the individual analyst forecast experience by } \\
\text { the number of quarters the analyst has issued forecasts for the target } \\
\text { company prior to the management capex guidance year; }\end{array}$ \\
\hline ALLSTAR & $=$ & $\begin{array}{l}\text { Indicator variable equal to one if at least one analyst capex forecast } \\
\text { among individual analyst capex forecasts is issued by top-three ranked } \\
\text { all-star analysts. All-star analysts are identified from Institutional } \\
\text { Investor magazine (II)'s All-American Research ranking; }\end{array}$ \\
\hline SYNCH_HIGH & $=$ & $\begin{array}{l}\text { Indicator variable equal to one if the firm-year level of investment } \\
\text { synchronicity with macroeconomic and industry-level news is greater } \\
\text { than the sample median and zero otherwise. We calculate the investment } \\
\text { synchronicity using } R^{2} \text { from the following regression: }\end{array}$ \\
\hline
\end{tabular}

$C_{A P X Y G_{i, t}}=\beta_{0}+\beta_{1} S U M O R D E R G_{i, t}+\beta_{2} I N D R E V T Q G_{i, t}+\varepsilon_{i, t}$

$C A P X Y G$ is a seasonal growth of quarterly capex investment. $S U M O R D E R G$ is a seasonal growth of quarterly new order for capital goods. INDREVTQG is a seasonal growth of quarterly SIC 2-digit

\footnotetext{
${ }^{1}$ Of 21 statistical tests presented below, 18 are in predicted directions, 16 of which are statistically significant, one is not in the predicted direction and statistically insignificant, and two are not in predicted directions.
} 
UNFAVOR

ABILITYLOW

LONGHORZ

BADNEWS industry revenue. We obtain new order data from the website: https://fred.stlouisfed.org/series/UNXANO;

$=$ Indicator variable equal to one if analysts' most recent consensus recommendations prior to managers' capex guidance include at least one "SELL" recommendation and zero otherwise. Recommendation summary file in IBES presents analyst consensus recommendations in terms of percentage of "Buy", "Hold", or "Sell" recommendations;

$=$ Indicator variable equal to one if the average management forecast accuracy is lower than the sample median and zero otherwise. We measure management forecast accuracy using the average of all management annual earnings forecast accuracy issued during the two years prior to capex guidance year (i.e., accuracy of an annual earnings forecast is measured as the absolute value of the management EPS forecast less the most recent analyst EPS forecast divided by the end-ofprior-year stock price, multiplied by (-1);

$=$ Indicator variable equal to one if log sum of unexercisable stock options and restricted stocks is greater than the sample median and zero otherwise; and

$=$ Indicator variable equal to one if $C A R \_5 D A Y<0$ and zero otherwise.

\section{OA-1. Cross-sectional validity tests for $\mathrm{H} 1 \mathrm{a}$ and $\mathrm{H} 1 \mathrm{~b}$}

We first present validity tests for $\mathrm{H} 1 \mathrm{a}$ and $\mathrm{H} 1 \mathrm{~b}$ using cross-sectional measures for analyst expertise, analyst information advantage, analyst incentives and additional Langberg and Sivaramakrishnan (2010) empirical predictions.

\section{OA-1.1 Analyst forecast diversity, experience, and all-star analyst following}

We control for industry capex growth (INDCPXGROWTH) and industry-mean efficiency (CPXGROWTH_Q1) in Table 3 to provide evidence that our findings are not attributable to managers and analysts using commonly available information. We further address this concern by investigating whether our test results vary with three analyst characteristics that capture analyst expertise, which we measure by forecast diversity, firm-specific forecasting experience, and allstar analysts' following. Analyst forecast diversity is estimated by averaging across all analysts the number of items among sales revenue, earnings and capex each analyst forecasts during the 
fiscal year immediately prior to the capex forecast year. Analyst firm-specific experience is estimated by averaging across all analysts the number of quarters in which each analyst has issued any forecasts for the firm prior to the capex forecast year. ${ }^{2}$ All-star analysts are indicated by Institutional Investor magazine's All-America Research Team awards. ${ }^{3}$ For these measures in order, indicator variables DIVERSE_HIGH and EXP_HIGH reflect above-sample median values and ALLSTAR equals to one if at least one among individual analyst capex forecasts is issued by a top-three-ranked all-star analyst.

Table OA-1.1 reports results for cross-sectional tests using DIVERSE_HIGH, EXP_HIGH, and ALLSTAR in Panels A, B, and C, respectively. Coefficients on FEEDBACK*DIVERSE_HIGH in Panel A and FEEDBACK* EXP_HIGH in Panel B are significantly positive, consistent with managerial learning being more reflective of higher quality analyst feedback than commonly available information. Panel C of Table OA-1.1 confirms in Column (1) that managerial capex adjustments are more reflective of all-star analyst feedback, another indicator of analyst quality. There is no significant relation for capex guidance revisions in Column (2), perhaps reflecting longer-term learning.

[Insert Table OA-1.1 here]

\footnotetext{
${ }^{2}$ We find that analysts' forecast diversity is significantly and positively correlated $(=0.099)$ with analysts' firmspecific experience, consistent with these measures reflecting higher analyst quality. A survey of professional practice for share valuation conducted by Pinto et al. (2019) shows that $92.8 \%$ and $78.8 \%$ of respondents use a market multiples approach and a discounted cash flow (DCF) approach, respectively. Conditional on their use of these approaches, respondents indicated that the percentage of analyses to which they apply a market multiples approach and a DCF approach is $68.6 \%$ and $59.5 \%$, respectively. Because the DCF approach requires more component forecasts than the market multiples approach, forecast diversity can proxy for analyst quality.

${ }^{3}$ We thank Michael Jung at University of Delaware for generously sharing the data.
} 


\section{OA-1.2. Investment synchronicity with macroeconomic and industry-level news}

Hutton et al. (2012) find that analysts (managers) have an information advantage at the macroeconomic (firm) level and comparable forecasting ability at the industry level. Thus, if a firm's capital investments are more synchronized with macro-level news, analyst feedback to managerial capex guidance is likely more informative. Therefore, we predict that $\mathrm{H} 1$ relations will be stronger for firms with higher investment synchronicity. We measure investment synchronicity using the $R^{2}$ from a regression of seasonal growth in quarterly capital expenditures on seasonal growth in the value of manufacturers' quarterly new orders for capital goods and the seasonal growth in SIC 2-digit industry-level quarterly sales revenue. ${ }^{4,5}$ We estimate this regression using the 12-quarter data prior to the capex guidance issuance quarter.

Table OA-1.2 reports that the relation between managerial capex adjustments and analyst feedback is significantly more positive with higher investment synchronicity, whereas the relation between capex guidance revisions and analyst feedback is positive but statistically insignificant. Albeit weak, these findings are consistent with a more positive relation between analyst feedback and managerial learning when analysts have an informational advantage over managers.

\footnotetext{
${ }^{4}$ Specifically, we use the time series of value of manufacturers' new orders for capital goods: nondefense capital goods excluding aircraft industries (UNXANO) available at https://fred.stlouisfed.org/series/UNXANO. We compute a seasonal quarterly growth rate of a variable by comparing the value of the current quarter with the value of the prior year same quarter.

${ }^{5}$ Hutton et al. (2012) investigate the relative information advantage of managers versus analysts on earnings forecasts. In their study, they measure analysts' information advantage in earnings forecasts by the ability of Gross Domestic Product $(G D P)$, energy costs (Energy), or the spread between the 30-year mortgage rate and the one-year Treasury Bill rate (Spread) to explain earnings. The presumption is that analysts have macroeconomic expertise that gives them an advantage in predicting economy-wide factors beyond managers' control. In our study, our focus is analysts' information advantage in capex forecasts. Since a firm's capex constitutes an element of economy-wide demand for capital goods and it is influenced by industry-wide demand conditions, the information advantage of analysts in predicting capex forecasts is likely to derive from their informational expertise in manufacturers' aggregate new order for capital goods and industry-level sales revenues rather than for GDP, Energy or Spread. Indeed, we find that growth in aggregate capital goods orders and industry sales revenue well explains growth in capex (mean $\mathrm{R}^{2}=30.4 \%$ ) and better than growth in GDP, Energy or Spread (mean R ${ }^{2}=26.7 \%, 22.3 \%$, and $22.6 \%$, respectively). This finding lends support to the use of investment synchronicity in our cross-sectional tests. When we use Hutton et al.'s (2012) synchronicity measures in place of ours, results for H1 do not vary with their measures, suggesting that noise in Hutton's measures we adapted to estimate analysts' informational advantage in capex forecasts reduces the power of tests.
} 
[Insert Table OA-1.2 here]

\section{OA-1.3. Analyst recommendations, access and feedback informativeness}

Whereas prior findings indicate that analysts issuing unfavorable recommendations may have less access to managers than those issuing favorable recommendations (e.g., Lin and McNichols 1998; Michaely and Womack 1999; Chen and Matsumoto 2006; Feng and McVay 2010), Mayew et al. (2020) find that analysts issuing unfavorable recommendations have longer dialogues and more interactions with managers during conference calls. Consistent with greater potential for managerial learning suggested by the Mayew et al. (2020) findings, we first find that the presence of a "sell" or "underperform" recommendation is significantly and positively correlated with the magnitude of an analyst's capex guidance feedback deviation (Pearson correlation $=0.049, p$-value $<0.01)$. To examine whether managerial learning is greater from analysts issuing unfavorable recommendations, we define indicator variable UNFAVOR to have a value of one if the most recent consensus recommendations prior to a manager's capex guidance includes at least one "sell" recommendation and zero otherwise. ${ }^{6}$ Table OA-1.3 reports that the interaction between analyst feedback and UNFAVOR is significantly positive in explaining managers' capex guidance errors but insignificantly positive in explaining managers' capex revisions. These results suggest that managers, while less inclined to incorporate feedback from analysts issuing unfavorable recommendations in their guidance revisions, perhaps due to less access, eventually reflect these analysts' feedback in capex investment decisions. ${ }^{7}$

\footnotetext{
${ }^{6}$ IBES codes analysts" unfavorable recommendations as either "sell" or "underperform" at the individual analyst level and at the summary consensus level, IBES provides the "sell" percentage of total recommendations by combining individual "sell" and "underperform" recommendations as "sell" cases. In our sample, $40 \%$ of all firm-year observations receive at least one sell recommendation.

${ }^{7}$ Analysts who issue favorable recommendations may more cater to managers and this catering may inhibit the provision of valuable feedback. By contrast, analysts who issue unfavorable recommendations may less bias their reports to please managers and offer more informative feedback. We thank an anonymous reviewer for this insight.
} 
[Insert Table OA-1.3 here]

\section{OA-1.4. Additional Langberg and Sivaramakrishnan (2010) empirical predictions}

Langberg and Sivaramakrishnan (2010) also identify conditions where managers will be more desirous of analysts' feedback. Specifically, they predict that managers with less predictive ability, with long-term managerial incentives, and with grim firm outlooks will be more eager to seek analyst feedback and voluntarily disclose firm-value determinants like capex. To test these corroborative analytical predictions, we test H1 incorporating cross-sectional variations in (1) managers' forecasting competence, (2) managers' long-horizon incentive, and (3) bad news content within the capex guidance sample. ${ }^{8}$

Panel A of Table OA-1.4 reports cross-sectional regression results for $\mathrm{H} 1$ based on variations in managerial forecasting competence. We measure managerial forecasting competence using the average accuracy of management annual earnings forecasts issued during the two years prior to capex guidance year (measured as the absolute value of the management EPS forecast less the most recent analyst EPS forecast divided by the end-of-prior-year stock price, multiplied by 1). We set ABILITYLOW to be one if the average management forecast accuracy is lower than the sample median and zero otherwise. We find evidence, albeit weak, that manager's capex adjustments are more sensitive to analyst feedback when managerial forecasting ability is low, consistent with the Langberg and Sivaramakrishnan (2010) prediction. ${ }^{9}$

Panel B of Table OA-1.4 presents the test results for H1 conditional on managers' longhorizon incentives. We measure manager's long-horizon incentives using unvested stock-based

\footnotetext{
${ }^{8}$ Because our sample for testing H1 is composed of management capex guidance cases only, our empirical tests approximate but do not perfectly reflect the analytical context of Langberg and Sivaramakrishnan (2010).

${ }^{9}$ We restrict the test sample to the observations that issued management EPS forecasts during past two years. Drastic reductions in sample size by $62.1 \%$ and $63.1 \%$ in Columns (1) and (2), respectively, likely cause the weaker results.
} 
incentives (i.e., unexercisable stock options and restricted stocks) following Zhang and Gimeno (2016), who document that CEOs are less concerned by short-term stock price declines with the potential to damage the value of their stock-based incentive holdings if their unvested stock-based incentive portfolio is larger. ${ }^{10}$ Based on this evidence, we deem a manager as having a long-term orientation (i.e., $L O N G H O R Z=1$ ) if the $\log$ sum of unexercisable stock options and restricted shares is greater than the sample median and zero otherwise. Manager's capex adjustments and guidance revisions are both more sensitive to analyst feedback when managers have higher longhorizon incentives consistent with the Langberg and Sivaramakrishnan (2010) prediction.

Panel C of Table OA-1.4 reports test results for H1 conditional on bad news content released on the capex guidance date. Following Langberg and Sivaramakrishnan (2010), bad news is defined as negative share price reaction on the capex guidance date (i.e., BADNEWS $=1$ if CAR_5DAY $<0$ and zero otherwise). Results reveal that managerial adjustments to capex and guidance are smaller when news is bad, contrary to Langberg and Sivaramakrishnan's prediction, but consistent with the finding of Jayaraman and Wu (2020) (Table 3, citing Edmans et al. 2015) that negative-price feedback acts as a limit to informed traders' arbitrage activities. ${ }^{11}$ A possible interpretation is that more limited firm resources arising from business uncertainty and missed capital investment opportunities as reflected in bad news reactions to capex guidance (and earnings guidance jointly for $72.2 \%$ of our sample) may be associated with delayed managerial responses to related analyst feedback.

\footnotetext{
${ }^{10}$ We do not use the executive pay duration measure of Gopalan et al. (2014), which captures the mix of short-term and long-term executive pay, because their pay duration data are only available over the period 2006 to 2009, which has only a one-year overlap with our sample period 2009 to 2014.

${ }^{11}$ Jayaraman and $\mathrm{Wu}(2019)$ find that the feedback effect of a positive price reaction is stronger than that of a negative price reaction, consistent with the view that feedback acts as limit to arbitrage (Edmans et al. 2015). Specifically, managers' corrective actions upon receiving negative-price feedback discourages traders from collecting and trading on negative information because of potential diminishing returns from managers' corrective actions, thus making negative price feedback less informative.
} 
[Insert Table OA-1.4 here]

\section{OA-2. Monitoring of agency conflict as an alternative explanation}

A possible alternative explanation for managerial capex adjustments to analyst feedback in $\mathrm{H} 1$ is monitoring by analysts, investors and other capital providers that mitigates agency-conflictinduced opportunistic investments. To confirm that our results are not attributable to monitoring of agency conflicts, we re-estimate $\mathrm{H} 1$ regressions for a firm-year sub-sample with low agency conflict. Jensen (1986) documents that managers of low growth and high free cash flow (FCF) firms are likely involved in non-value-maximizing activities due to high agency cost problems. Following Jensen (1986), we classify low agency conflict firm-years as those with negative FCF and a Tobin's Q greater than the SIC 2-digit industry mean Tobin's Q. FCF is measured by (operating cash flow + investing cash flow + long-term debt issuance - long-term debt reduction + changes in current debt) / beginning of year net property, plant and equipment. Tobin's Q is measured by (market value of equity + total assets - book value of equity) / total assets. Table OA2 reports that both $\mathrm{H} 1 \mathrm{a}$ and $\mathrm{H} 1 \mathrm{~b}$ hold for low agency conflict conditions, making it unlikely that agency conflict monitoring explains reported $\mathrm{H} 1$ results. ${ }^{12,13}$

[Insert Table OA-2 here]

\footnotetext{
${ }^{12} \mathrm{H} 1$ is also supported when we use alternative definitions of a low agency conflict group (e.g., FCF $<0$ only or FCF $<$ sample median).

${ }^{13}$ Untabulated corporate governance comparisons indicate that firms issuing capex guidance exhibit greater institutional ownership, board size, board independence, and CEO-Chairman duality but lower free cash flows compared with those that do not issue capex guidance. Firms making larger capex adjustments among capex guidance issuers exhibit greater institutional ownership, lower free cash flows but are insignificantly different in board size, board independence and CEO-Chairman duality, compared with capex guidance firms with smaller capex adjustments. These univariate findings require a control for the differential monitoring impact of agency conflicts by governance variables, which we concisely implement with tests in Table OA-2.
} 


\section{OA-3. Investment efficiency validity tests for $\mathrm{H2}$}

In this section, we provide baseline evidence of an association between capex guidance issuance and capital investment efficiency that underpins the predictions of H2. Specifically, we consider reverse causality using simultaneous equations approach and Granger causality and multinomial logistic estimation of capital over- and under-investment, with findings that lend support to the investment efficiency model used for testing $\mathrm{H} 2$.

We begin by estimating the following regression:

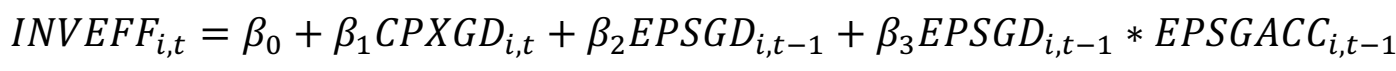

$$
\begin{aligned}
& +\beta_{4} \operatorname{INSTOWN}_{i, t-1}+\beta_{5} \text { ANALYST }_{i, t-1}+\beta_{6} F R Q_{i, t-1}+\beta_{7} L E V_{i, t-1} \\
& +\beta_{8} \text { FREECF }_{i, t-1}+\beta_{9} S T D C P X_{i, t-1}++\beta_{10} T_{O B I N Q_{i, t-1}}+\beta_{11} C F_{i, t} \\
& + \text { Industry } F E+\text { Year } F E+\varepsilon_{i, t} \text {, }
\end{aligned}
$$

where INVEFF is the absolute value of abnormal investment estimated using Equation (2) and multiplied by -1 for more intuitive interpretation. CPXGD is an indicator variable equal to one if the firm issues capex guidance for the forecasting target year during the first quarter of year $t$ and zero otherwise. We predict $\beta_{1}$ to be positive.

Included in Equation (OA3.1) are additional control variables found to influence investment efficiency in prior empirical and theoretical studies. Specifically, we add a dummy variable for management earnings guidance (EPSGD) and its interaction with management earnings forecast accuracy (EPSGD * EPSGACC) because Goodman et al. (2014) find that the quality of management earnings guidance measured by accuracy of management earnings forecasts is positively associated with investment efficiency. Institutional investor ownership (INSTOWN) and the number of following analysts (ANALYST) control for a positive impact of 
investor monitoring on investment efficiency. ${ }^{14} \mathrm{We}$ include financial reporting quality $(F R Q)$ because Biddle et al. (2009) document a positive relation between financial reporting quality and investment efficiency. We include leverage ( $L E V)$ and free cash flow (FREECF) because a high leverage firm is likely to under-invest (Myers 1977) and a firm with large free cash flow is likely to over-invest (Jensen 1986). ${ }^{15}$ We also include the standard deviation of capex (STDCPX) because greater volatility reduces the probability that actual investment achieves normal investment (Goodman et al. 2014). Following the suggestion of Chen et al. (2018), we add TOBINQ and $C F$, the regressors in Equation (OA3.1), to eliminate biases resulting from the use of absolute residuals as a measure of investment efficiency. Finally, we control for industry (SIC 2-digit) and year fixed effects.

To address the possibility of reverse causality we estimate two equations simultaneously investment efficiency Equation (OA3.1) and capex guidance issuance decision Equation (OA3.2) following Maddala (1983, pp. 242-247):

$$
\begin{aligned}
\text { CPXGD }_{i, t}= & \beta_{0} \\
& +\beta_{1} \text { INVEFF }_{i, t}+\beta_{2} \text { CPXGD }_{i, t-1}+\beta_{3} \text { EPSGD }_{i, t-1}+\beta_{4} \text { INSTOWN }_{i, t-1} \\
& +\beta_{5} \text { ANALYST }_{i, t-1}+\beta_{6} \text { STDCPX }_{i, t-1}+\beta_{7} \text { STDRET }_{i, t-1}+\beta_{8} \text { CAPINT }_{i, t-1} \\
& +\beta_{9} \text { ROA }_{i, t-1}+\beta_{10} \text { MTB }_{i, t-1}+\beta_{11} \text { RISKIND }_{i, t-1}+\beta_{12} \text { DISSEM_MEDIA }_{i, t-1} \\
& + \text { Industry FE }_{-} \text {Year FE }+\varepsilon_{i, t} .
\end{aligned}
$$

Specifically, we calculate the predicted value of the current year's capex guidance decision variable $\left(C P X G D_{i, t}\right)$ from the first-stage regression that employs all of the exogenous variables in Equation (OA3.2), and then use this predicted value to estimate Equation (OA3.1). In Equation

\footnotetext{
${ }^{14}$ The Pearson correlation between firm size (LOGAT) and the number of analysts following the firm (ANALYST) is 0.545 . Because of this high correlation, we do not include firm size in the equation. The results remain unchanged if we replace $A N A L Y S T$ with $L O G A T$.

${ }^{15}$ We set FREECF to be the level of free cash flow when it is positive and zero otherwise. Jensen (1986) predicts that agency problems are severe when the organization generates substantial free cash flow. In line with his prediction, we define FREECF to capture the degree of agency problems theorized by Jensen.
} 
(OA3.2), we include the current year's absolute value of abnormal capex multiplied by -1 $\left(I N V E F F_{i, t}\right)$ to proxy for managers' beliefs regarding their capex efficiency type. We include a prior-year capex guidance issuance dummy $(C P X G D)$ to control for capex guidance policy. We include the prior-year earnings guidance dummy variable (EPSGD) to control for voluntary disclosure tendency. Institutional ownership (INSTOWN) and the number of analysts following the firm (ANALYST) control for investors' information demand (Chapman and Green 2018). Capex volatility $(S T D C P X)$ and return volatility (STDRET) control for difficulty in predicting capex. High capex and return volatility increases investor demand for capex guidance but discourages managers from providing it because of higher risk of missing the guidance. Investors demand more information for capex if capital intensity (CAPINT) is higher (Lu and Tucker 2012). High profitability $(R O A)$ and growth opportunities $(M T B)$ are not sustainable without capital expenditures; thus, investors may demand more information about capex when profitability or growth opportunities are higher. ${ }^{16}$ We include the high litigation risk industry dummy (RISKIND) to control for litigation risk (Francis et al. 1994; Matsumoto 2002).

A simultaneous equations approach requires exclusion restrictions to identify a solution for Equation (OA3.1). Specifically, Equation (OA3.2) should include at least one exogenous variable that is correlated with the guidance decision in Equation (OA3.2) but uncorrelated with the disturbance in Equation (OA3.1) (Greene 2000). In our test, prior-year dissemination media coverage dummy (DISSEM_MEDIA) is likely to satisfy the exclusion restriction requirement. DISSEM_MEDIA is an indicator variable that equals one if the firm's prior-year first-quarter capex guidance receives coverage in at least one news flash article (i.e., a news article comprising a

\footnotetext{
${ }^{16}$ When we replace the market-to-book ratio with prior-year sales growth, the results are qualitatively identical.
} 
headline and no body text). ${ }^{17}$ Managers are likely to continue providing capex guidance once their guidance is covered by dissemination media since a large number of market participants will expect and rely on it. On the other hand, since the dissemination media primarily distributes summaries of firm-generated guidance without editorial content, media coverage by news flash articles cannot readily serve as a medium for analyst feedback learning by managers. Indirectly, coverage by dissemination media could increase monitoring by investors and thus increase investment efficiency. However, this indirect effect would be captured by institutional ownership (INSTOWN) and the number of analysts (ANALYST) following the firm in Equation (OA3.1); thus, the disturbance in Equation (OA3.1) should be uncorrelated with dissemination media coverage. ${ }^{18}$ Panel A of Table OA-3 presents estimation results where Column(1) shows the coefficient for $I N V E F F_{t}$ to be positive and significant, consistent with a relation between capex guidance and investment efficiency. Column (2) shows the coefficient for $C P X G D_{t}$ to be significantly positive (0.895, $p$-value $<0.01)$ after controlling for reverse causality, thus lending support to the investment efficiency model used for testing H2. Among control variables, ANALYST is significantly positively associated with capital investment efficiency, consistent with a positive impact of investor monitoring on investment efficiency. The coefficient for $F R Q$ is significantly positive, consistent with Biddle et al. (2009). The coefficient for STDCPX is significantly negative, consistent with difficulty in achieving efficient investment when investment is volatile (Goodman et al. 2014). Column (3) reports Granger causality tests of whether capex guidance leads investment efficiency. Specifically, we add in Equation (OA3.1) one-year lagged investment

\footnotetext{
${ }^{17}$ We identify news flash article coverage of capex guidance news through RavenPack's Dow Jones Edition database. 18 The Pearson correlation between investment efficiency (INVEFF) and dissemination media coverage (DISSEM_MEDIA) is 0.04 . When we run a stand-alone regression after adding DISSEM_MEDIA as an independent variable in Equation (OA3.1), the coefficient for DISSEM_MEDIA is insignificant. Moreover, the test for the null of a weak instrument is strongly rejected (Cragg-Donald Wald F-stat $=298.68)$. These results indicate that dissemination media coverage is a good instrument in the sense of satisfying the exclusion restriction.
} 
efficiency as an independent variable and test the significance of capex guidance. Results in Column (3) are qualitatively identical to those of the second stage regression in Column (2).

We also test the prediction of a positive relation between capex guidance issuance and capital investment efficiency separately for under- and over-investment using a multinomial logit regression version of the regression in Panel B of Table OA-3 following Biddle et al. (2009). Specifically, we classify firms into quartiles based on the magnitude of residuals in Equation (2) (i.e., deviations of actual capex from predicted capex). The top quartile, which captures a relatively large positive deviation from normal investment, is classified as an over-investment group and the bottom quartile, which captures a relatively large negative deviation from normal investment, is classified as an under-investment group. The middle two quartiles, which exhibit relatively small positive and negative deviations from normal investment, are used as a benchmark normal investment group. Using these over-investment, under-investment, and normal investment groups as categories of the dependent variable, we run a multinomial logit regression with the same set of independence variables in Column (2) of Panel A in Table OA-3. Results in Panel B show that capex guidance issuance is negatively associated with under- and over-investment, consistent with the finding in Panel A. Results for control variables are generally consistent with Panel A with the following exceptions. First, Myers (1977) implies that a higher leverage firm is likely to underinvest and less likely to over-invest. Results in Panel B confirm that leverage is positively associated with under-investment and negatively associated with over-investment. Second, the FCF theory of Jensen (1986) implies that a higher FCF firm is likely to over-invest and less likely to under-invest. Results in Panel B confirm that FCF is positively associated with over-investment and negatively associated with under-investment. 
The economic impact of capex guidance is also not negligible. Results in Table OA-3 show that capex guidance firms have $89 \%$ (113\%) higher investment efficiency than non-capex guidance firms in Column (2) (Column (3)) of Panel A. The relative probability of under- (over-) investment of capex guidance firms rather than normal investment is $0.9 \%(5.7 \%)$ lower for capex guidance firms than non-guidance firms in Panel B. Considered altogether, this set of findings for a simultaneous equations approach, Granger causality, capital over- and under-investment and economic significance lends support to the investment efficiency measure used for testing H2.

[Insert Table OA-3 here] 


\section{Table OA-1.1. Analyst characteristics}

This table presents regression results conditioned by analyst characteristics. Specifically, Panel A, B, and $\mathrm{C}$ test for associations between analyst feedback $\left(F E E D B A C K_{t}\right)$, and managerial capex adjustments in Column (1) and guidance revisions in Column (2) conditioned by the level of analyst forecast diversity (DIVERSE_HIGH), analysts' firm-specific experience (EXP_HIGH), and all-star analysts' coverage of the firm (ALLSTAR), respectively. See Appendix A for variable definitions. Standard errors are clustered by firm. $* * *, * *, *$ indicate statistical significance at the $1 \%, 5 \%$, and $10 \%$ levels for two-tailed tests, respectively. One-tailed tests are used only when a sign is predicted.

\section{Panel A. Analyst forecast diversity}

\begin{tabular}{|c|c|c|c|c|c|}
\hline \multirow[b]{2}{*}{ Variables } & \multirow[b]{2}{*}{ Pred. } & \multicolumn{2}{|c|}{$\begin{array}{l}\text { (1) Actual capex adjustment } \\
\text { Dep. Var. }=C P X G D \_E R R_{t}\end{array}$} & \multicolumn{2}{|c|}{$\begin{array}{l}\text { (2) Capex guidance revision } \\
\text { Dep. Var. }=C P X G D \_R E V_{t}\end{array}$} \\
\hline & & & t-stat. & Coeff. & t-stat \\
\hline INTERCEPT & & 0.695 & 0.32 & -0.385 & -0.67 \\
\hline$F E E D B A C K_{t}$ & & 0.390 & $2.82 * * *$ & 0.015 & 0.67 \\
\hline DIVERSE_HIGH & & 0.433 & 0.99 & 0.077 & 0.52 \\
\hline FEEDBACK ${ }_{t}{ }^{*} D I V E R S E_{-} H I G H$ & + & 0.376 & $2.57 * * *$ & 0.090 & $2.34 * * *$ \\
\hline INDCPXGROWTH $H_{t}$ & & 0.022 & $1.96^{*}$ & 0.001 & 0.36 \\
\hline$C P X G R O W T H_{-} Q 1_{t}$ & & 0.017 & $6.65^{* * *}$ & 0.002 & $3.20 * * *$ \\
\hline$C A R_{-} 5 D A Y_{t}$ & & 0.218 & 1.24 & 0.070 & 1.06 \\
\hline Fixed Effects & & Industry, Y & ndustry*Year & Industry, Y & dustry*Year \\
\hline$N$ & & & & & \\
\hline $\mathrm{R}^{2}$ & & & & & \\
\hline
\end{tabular}

\section{Panel B. Analyst experience}

\begin{tabular}{|c|c|c|c|c|c|}
\hline \multirow[b]{2}{*}{ Variables } & \multirow[b]{2}{*}{ Pred. } & \multicolumn{2}{|c|}{$\begin{array}{l}\text { (1) Actual capex adjustment } \\
\text { Dep. Var. }=C P X G D_{-} E R R_{t}\end{array}$} & \multicolumn{2}{|c|}{$\begin{array}{l}\text { (2) Capex guidance revision } \\
\text { Dep. Var. }=C P X G D_{-} R E V_{t}\end{array}$} \\
\hline & & & t-stat. & & t-stat \\
\hline INTERCEPT & & 0.725 & 0.33 & -0.209 & -0.36 \\
\hline$F E E D B A C K_{t}$ & & 0.528 & $4.17 * * *$ & 0.043 & $1.67^{*}$ \\
\hline$E X P_{-} H I G H$ & & 0.219 & 0.54 & -0.212 & -1.59 \\
\hline FEEDBACK ${ }_{t}^{*} E X P_{-} H I G H$ & + & 0.252 & $1.72 * *$ & 0.078 & $2.01 * *$ \\
\hline INDCPXGROWTH $H_{t}$ & & 0.024 & $2.23 * *$ & 0.001 & 0.33 \\
\hline$C P X G R O W T H_{-} Q 1_{t}$ & & 0.017 & $6.49 * * *$ & 0.002 & $3.06 * * *$ \\
\hline$C A R_{-} 5 D A Y_{t}$ & & 0.248 & 1.39 & 0.075 & 1.14 \\
\hline Fixed Effects & & Industry, Y & ndustry*Year & Industry, Y & ustry*Year \\
\hline$N$ & & & & & \\
\hline $\mathrm{R}^{2}$ & & & & & \\
\hline
\end{tabular}

Panel C. All-star analysts' coverage of the firm

\begin{tabular}{l|c|cc}
\hline & (1) Actual capex adjustment & \multicolumn{2}{|c}{ (2) Capex guidance revision } \\
Variables & Pep. Var. $=C P X G D \_E R R_{t}$ & Dep. Var. $=C P X G D \_R E V_{t}$ \\
Coeff. & t-stat. & Coeff. & t-stat \\
\hline
\end{tabular}




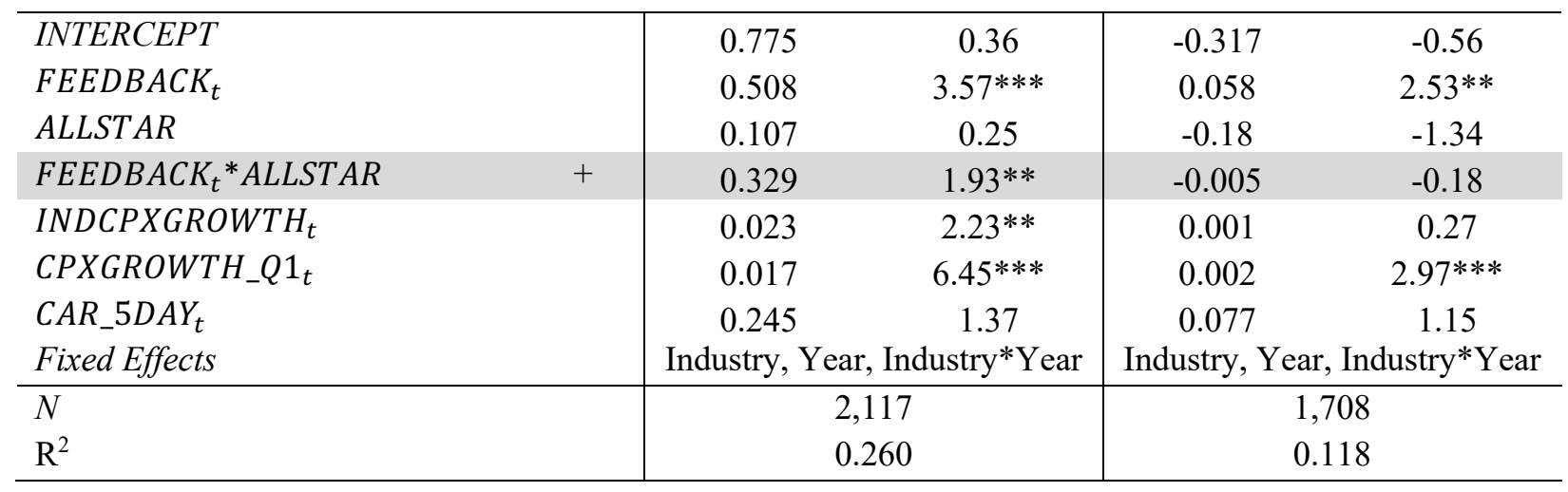


Table OA-1.2. Investment synchronicity with macroeconomic and industry-level news

This table presents cross-sectional test results conditioned by investment synchronicity with macroeconomic and industry-level news. Specifically, this table tests for associations between analyst feedback $\left(F E E D B A C K_{t}\right)$, and managerial capex adjustments in Column (1) and guidance revisions in Column (2) conditioned by the level of synchronicity (SYNCH_HIGH). See Appendix A for variable definitions. Standard errors are clustered by firm. $* * *, * *, *$ indicate statistical significance at the $1 \%, 5 \%$, and $10 \%$ levels for two-tailed tests, respectively. One-tailed tests are used only when a sign is predicted.

\begin{tabular}{|c|c|c|c|c|c|}
\hline \multirow[b]{2}{*}{ Variables } & \multirow[b]{2}{*}{ Pred. } & \multicolumn{2}{|c|}{$\begin{array}{l}\text { (1) Actual capex adjustment } \\
\text { Dep. Var. }=C P X G D E R R_{+}\end{array}$} & \multicolumn{2}{|c|}{$\begin{array}{l}\text { (2) Capex guidance revision } \\
\text { Dep. Var. }=C P X G D \_R E V_{t}\end{array}$} \\
\hline & & Coeff. & t-stat. & Coeff. & t-stat \\
\hline INTERCEPT & & 1.323 & 0.60 & -0.432 & -0.75 \\
\hline$F E E D B A C K_{t}$ & & 0.592 & $4.91 * * *$ & 0.078 & $2.62 * * *$ \\
\hline SYNCH_HIGH & & -0.409 & -0.98 & 0.093 & 0.70 \\
\hline FEEDBACK ${ }_{t}^{*}$ SYNCH_HIGH & + & 0.294 & $1.43 *$ & 0.013 & 0.27 \\
\hline INDCPXGROWTH $H_{t}$ & & 0.021 & $1.97 * *$ & 0.001 & 0.36 \\
\hline$C P X G R O W T H_{-} Q 1_{t}$ & & 0.021 & $7.48 * * *$ & 0.003 & $3.38 * * *$ \\
\hline$C A R_{-} 5 D A Y_{t}$ & & 0.219 & 1.27 & 0.069 & 1.06 \\
\hline Fixed Effects & & \multicolumn{2}{|c|}{ Industry, Year, Industry*Year } & \multicolumn{2}{|c|}{ Industry, Year, Industry*Year } \\
\hline$N$ & & \multicolumn{2}{|c|}{2,113} & \multicolumn{2}{|c|}{1,706} \\
\hline $\mathrm{R}^{2}$ & & \multicolumn{2}{|c|}{0.255} & \multicolumn{2}{|c|}{0.122} \\
\hline
\end{tabular}


Table OA-1.3. Analyst recommendations as an incentive to provide feedback

This table presents cross-sectional results conditioned by analyst recommendation. Specifically, this table tests for associations between analyst feedback $\left(F E E D B A C K_{t}\right)$, and managerial capex adjustments in Column (1) and guidance revisions in Column (2) conditioned by analysts' unfavorable recommendation (UNFAVOR). See Appendix A for variable definitions. Standard errors are clustered by firm. ***, **, * indicate statistical significance at the $1 \%, 5 \%$, and $10 \%$ levels for two-tailed tests, respectively. One-tailed tests are used only when a sign is predicted.

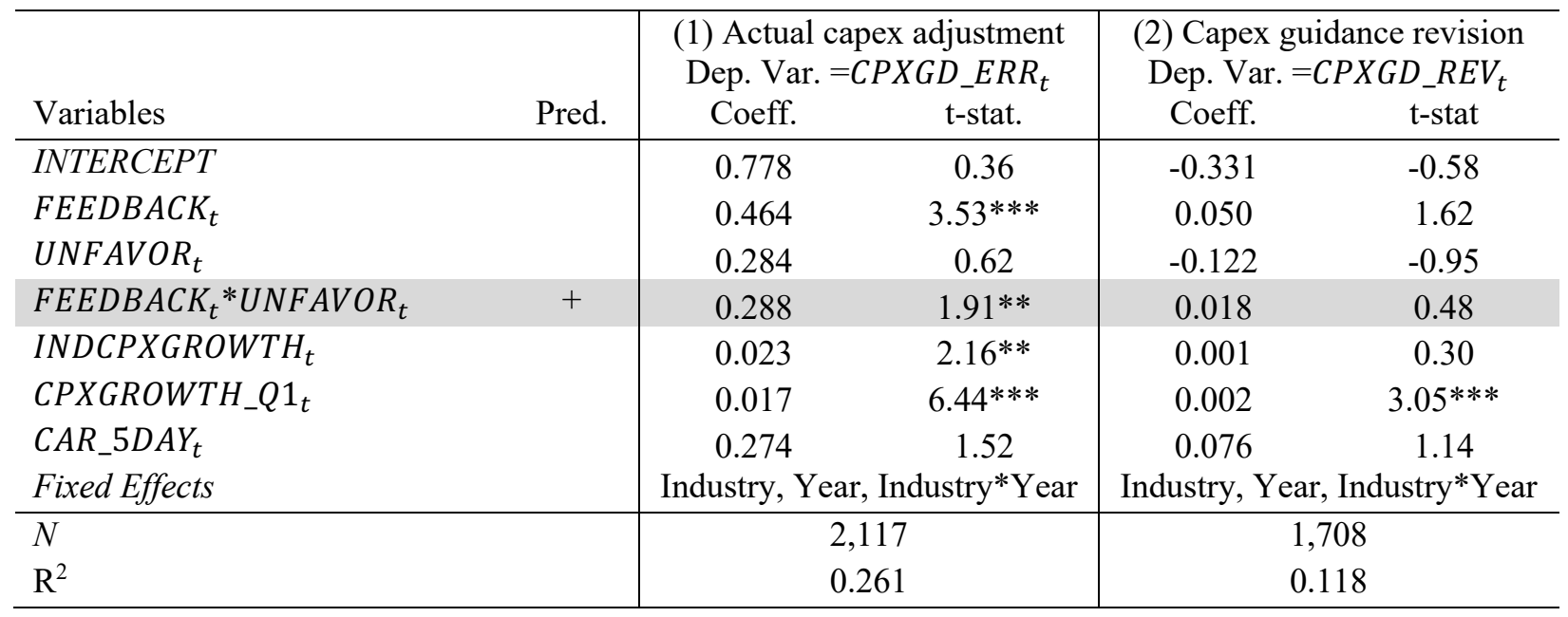


Table OA-1.4. Additional Langberg and Sivaramakrishnan (2010) empirical predictions

This table presents additional cross-sectional results predicted by Langberg and Sivaramakrishnan (2010). Specifically, this table tests for associations between analyst feedback $\left(F E E D B A C K_{t}\right)$, and managerial capex adjustments in Column (1) and guidance revisions in Column (2) conditioned by low management earnings forecasting ability (ABILITYLOW) in Panel A, managers' long-horizon incentive (LONGHORZ) in Panel B, and bad news content $(B A D N E W S)$ in Panel C. See Appendix A for variable definitions. Standard errors are clustered by firm. $* * *, * * *$ indicate statistical significance at the $1 \%, 5 \%$, and $10 \%$ levels for two-tailed tests, respectively. One-tailed tests are used only when a sign is predicted.

Panel A. Managerial forecasting competence

\begin{tabular}{|c|c|c|c|c|c|}
\hline \multirow[b]{2}{*}{ Variables } & \multirow[b]{2}{*}{ Pred. } & \multicolumn{2}{|c|}{$\begin{array}{l}\text { (1) Actual capex adjustment } \\
\text { Dep. Var. }=C P X G D_{-} E R R_{t}\end{array}$} & \multicolumn{2}{|c|}{$\begin{array}{l}\text { (2) Capex guidance revision } \\
\text { Dep. Var. }=C P X G D \_R E V_{t}\end{array}$} \\
\hline & & Coeff. & t-stat. & Coeff. & t-stat \\
\hline INTERCEPT & & -0.758 & -0.60 & -1.847 & $-5.85 * * *$ \\
\hline$F E E D B A C K_{t}$ & & 0.384 & $1.69 *$ & 0.002 & 0.12 \\
\hline ABILITYLOW & & 0.900 & 1.23 & 0.223 & 1.27 \\
\hline FEEDBACK $K_{t}^{*}$ ABILITYLOW & + & 0.311 & $1.33^{*}$ & -0.030 & -0.67 \\
\hline INDCPXGROWTH $H_{t}$ & & -0.003 & -0.18 & 0.002 & 0.39 \\
\hline$C P X G R O W T H_{-} Q 1_{t}$ & & 0.018 & $3.62 * * *$ & 0.002 & 1.48 \\
\hline$C A R_{-} 5 D A Y_{t}$ & & 0.278 & 1.05 & -0.058 & -0.53 \\
\hline Fixed Effects & & \multicolumn{2}{|c|}{ Industry, Year, Industry*Year } & \multicolumn{2}{|c|}{ Industry, Year, Industry*Year } \\
\hline$N$ & & \multicolumn{2}{|c|}{803} & \multicolumn{2}{|c|}{631} \\
\hline $\mathrm{R}^{2}$ & & \multicolumn{2}{|c|}{0.240} & \multicolumn{2}{|c|}{0.102} \\
\hline
\end{tabular}

Panel B. Manager's long-horizon incentive

\begin{tabular}{|c|c|c|c|c|c|}
\hline \multirow[b]{2}{*}{ Variables } & \multirow[b]{2}{*}{ Pred. } & \multicolumn{2}{|c|}{$\begin{array}{l}\text { (1) Actual capex adjustment } \\
\text { Dep. Var. }=C P X G D \_E R R_{t}\end{array}$} & \multicolumn{2}{|c|}{$\begin{array}{l}\text { (2) Capex guidance revision } \\
\text { Dep. Var. }=C P X G D \_R E V_{t}\end{array}$} \\
\hline & & Coeff. & t-stat. & Coeff. & t-stat \\
\hline INTERCEPT & & 1.104 & 0.46 & -0.323 & -0.57 \\
\hline$F E E D B A C K_{t}$ & & 0.522 & $2.80 * * *$ & 0.007 & 0.23 \\
\hline$L O N G H O R Z$ & & 0.021 & 0.05 & -0.080 & -0.62 \\
\hline FEEDBACK ${ }_{t}^{*}$ LONGHORZ & + & 0.275 & $1.31 *$ & 0.085 & $2.34 * *$ \\
\hline INDCPXGROWTH $H_{t}$ & & 0.010 & 1.00 & 0.001 & 0.45 \\
\hline$C P X G R O W T H_{-} Q 1_{t}$ & & 0.015 & $4.95^{* * *}$ & 0.002 & $2.32 * *$ \\
\hline$C A R_{-} 5 D A Y_{t}$ & & 0.332 & $1.97 * *$ & 0.085 & 1.30 \\
\hline Fixed Effects & & Industry, & lustry*Year & Industry, Y & Istry*Year \\
\hline$N$ & & & & & \\
\hline $\mathrm{R}^{2}$ & & & & & \\
\hline
\end{tabular}

Panel C. Bad news defined by a negative stock market reaction (i.e., CAR_5DAYS $<0$ )

\begin{tabular}{|c|c|c|c|c|c|}
\hline \multirow[b]{2}{*}{ Variables } & \multirow[b]{2}{*}{ Pred. } & \multicolumn{2}{|c|}{$\begin{array}{l}\text { (1) Actual capex adjustment } \\
\text { Dep. Var. }=C P X G D_{-} E R R_{t}\end{array}$} & \multicolumn{2}{|c|}{$\begin{array}{l}\text { (2) Capex guidance revision } \\
\text { Dep. Var. }=C P X G D \_R E V_{t}\end{array}$} \\
\hline & & Coeff. & t-stat. & Coeff. & t-stat \\
\hline INTERCEPT & & 0.880 & 0.40 & -0.318 & -0.56 \\
\hline
\end{tabular}




\begin{tabular}{|c|c|c|c|c|c|}
\hline$F E E D B A C K_{t}$ & & 0.765 & $7.18^{* * *}$ & 0.133 & $5.01 * * *$ \\
\hline$B A D N E W S_{t}$ & & -0.093 & -0.18 & -0.023 & -0.13 \\
\hline$F E E D B A C K_{t}{ }^{*} B A D N E W S_{t}$ & + & -0.305 & $-2.11 * *$ & -0.134 & $-4.51 * * *$ \\
\hline INDCPXGROWTH $H_{t}$ & & 0.023 & $2.12 * *$ & 0.001 & 0.45 \\
\hline$C P X G R O W T H \_Q 1_{t}$ & & 0.017 & $6.55^{* * *}$ & 0.002 & $3.26 * * *$ \\
\hline$C A R_{-} 5 D A Y_{t}$ & & 0.238 & 0.97 & 0.086 & 0.96 \\
\hline Fixed Effects & & Industry, & ddustry*Year & Industry, Ye & ndustry*Year \\
\hline$N$ & & \multicolumn{2}{|c|}{2,117} & \multicolumn{2}{|c|}{1,708} \\
\hline $\mathrm{R}^{2}$ & & \multicolumn{2}{|c|}{0.262} & \multicolumn{2}{|c|}{0.135} \\
\hline
\end{tabular}




\section{Table OA-2. Test of $\mathrm{H} 1$ when ex-ante agency costs are low}

This table presents regression tests for associations between analyst feedback (FEEDBACK $t$ ), and managerial capex adjustments in Column (1) and guidance revisions in Column (2) when the sample is limited to low agency cost cases. We identify observations have low agency costs if the firm-year level of free cash flow is negative and the leverage is lower than the sample median. See Appendix A for variable definitions. Standard errors are clustered by firm. $* * *, * *, *$ indicate statistical significance at the $1 \%, 5 \%$, and $10 \%$ levels for two-tailed tests, respectively. One-tailed tests are used only when a sign is predicted.

\begin{tabular}{|c|c|c|c|c|c|}
\hline \multirow[b]{2}{*}{ Variables } & \multirow[b]{2}{*}{ Pred. } & \multicolumn{2}{|c|}{$\begin{array}{l}\text { (1) Actual capex adjustment } \\
\text { Dep. Var. }=C P X G D_{-} E R R_{t}\end{array}$} & \multicolumn{2}{|c|}{$\begin{array}{l}\text { (2) Capex guidance revision } \\
\text { Dep. Var. }=C P X G D_{-} R E V_{t}\end{array}$} \\
\hline & & Coeff. & t-stat. & Coeff. & t-stat \\
\hline INTERCEPT & & 23.721 & $6.84 * * *$ & -28.425 & $-6.03 * * *$ \\
\hline$F E E D B A C K_{t}$ & + & 0.585 & $2.09 * *$ & 0.086 & $2.10 * *$ \\
\hline INDCPXGROWTH $H_{t}$ & & 0.017 & 0.26 & 0.012 & 0.68 \\
\hline$C P X G R O W T H_{-} Q 1_{t}$ & & 0.036 & $2.51 * *$ & 0.004 & 1.28 \\
\hline$C A R_{-} 5 D A Y_{t}$ & & 1.203 & 1.29 & 0.291 & $1.82 *$ \\
\hline Fixed Effects & & \multicolumn{2}{|c|}{ Industry, Year, Industry*Year } & \multicolumn{2}{|c|}{ Industry, Year, Industry*Year } \\
\hline$N$ & & \multicolumn{2}{|c|}{157} & \multicolumn{2}{|c|}{124} \\
\hline $\mathrm{R}^{2}$ & & \multicolumn{2}{|c|}{0.540} & \multicolumn{2}{|c|}{0.497} \\
\hline
\end{tabular}




\section{Table OA-3. Investment efficiency validity tests for $\mathbf{H} 2$}

This table presents tests of associations between capex guidance and capital investment efficiency. Columns (1) and (2) of Panel A report regression results using a simultaneous equations approach. Column (3) of Panel A presents Granger-causality test results. Panel B presents multinomial regression results. All variables have $t-1$ time subscripts except where indicated. See Appendix A for variable definitions. Standard errors are clustered by firm for the Granger causality test and multinomial logistic regression. ***, $* *, *$ indicate statistical significance at the $1 \%, 5 \%$, and $10 \%$ levels for two-tailed tests, respectively. Onetailed tests are used only when a sign is predicted.

Panel A. Simultaneous equations approach and Granger causality test

\begin{tabular}{|c|c|c|c|c|c|c|c|}
\hline \multirow[b]{2}{*}{ Variables } & \multirow[b]{2}{*}{ Pred. } & \multicolumn{2}{|c|}{$\begin{array}{c}(1) \\
\text { Dep. Var. } \\
=\operatorname{Pr}\left(C P X G D_{t}=1\right)\end{array}$} & \multicolumn{2}{|c|}{$\begin{array}{l}\text { (2) } \\
\text { Dep. Var. } \\
=I N V E F F_{t}\end{array}$} & \multicolumn{2}{|c|}{$\begin{array}{c}\text { Granger causality test } \\
\text { (3) } \\
\text { Dep. Var. } \\
=I N V E F F_{t}\end{array}$} \\
\hline & & Coeff. & z-stat. & Coeff. & t-stat & Coeff. & t-stat \\
\hline INTERCEPT & & -1.295 & $-9.47 * * *$ & -9.538 & $-9.48 * * *$ & -7.916 & $-7.14 * * *$ \\
\hline$C P X G D_{t}$ & + & & & 0.895 & $3.91 * * *$ & 1.138 & $2.65^{* * *}$ \\
\hline$I N V E F F_{t}$ & & 0.020 & $3.21 * * *$ & & & & \\
\hline$I N V E F F$ & & & & & & 0.196 & $8.07 * * *$ \\
\hline$C P X G D$ & & 1.831 & $39.22 * * *$ & & & & \\
\hline$E P S G D$ & & 0.357 & $6.97 * * *$ & 0.675 & 1.24 & 0.917 & $1.73^{*}$ \\
\hline$E P S G D^{*} E P S G A C C$ & & & & 8.458 & 0.60 & 10.355 & 1.13 \\
\hline INSTOWN & & 0.212 & $3.53 * * *$ & 0.003 & 0.01 & 0.246 & 0.40 \\
\hline$A N A L Y S T$ & & 0.087 & $2.11^{* *}$ & 1.906 & $4.93 * * *$ & 1.737 & $4.16^{* * *}$ \\
\hline$F R Q$ & & & & 22.312 & $6.35^{* * *}$ & 18.543 & $3.46 * * *$ \\
\hline$L E V$ & & & & 1.680 & 1.43 & 1.46 & 1.14 \\
\hline$F R E E C F$ & & & & -1.692 & $-11.79 * * *$ & -1.525 & $-4.3 * * *$ \\
\hline$S T D C P X$ & & -0.002 & $-2.07 * *$ & -0.065 & $-6.87 * * *$ & -0.042 & $-2.43 * *$ \\
\hline TOBINQ & & & & -2.486 & $-12.95 * * *$ & -2.272 & $-7.98 * * *$ \\
\hline$C F_{t}$ & & & & 0.138 & $2.29 * *$ & 0.111 & 0.75 \\
\hline STDRET & & 1.178 & $2.40 * *$ & & & & \\
\hline CAPINT & & 0.305 & $2.11^{* *}$ & & & & \\
\hline$R O A$ & & 0.366 & $1.86^{*}$ & & & & \\
\hline$M T B$ & & 0.000 & 0.10 & & & & \\
\hline RISKIND & & -0.037 & -0.52 & & & & \\
\hline DISSEM_MEDIA & & 0.820 & $6.62 * * *$ & & & & \\
\hline Fixed Effects & & Indus & Year & Indu & y, Year & Indus & , Year \\
\hline$N$ & & & & & 430 & & \\
\hline Pseudo (Adj) $\mathrm{R}^{2}$ & & & & & 144 & & \\
\hline
\end{tabular}

Panel B. Multinomial logistic regression

\begin{tabular}{|c|c|c|c|c|c|}
\hline \multirow[b]{2}{*}{ Variables } & \multirow[b]{2}{*}{ Pred. } & \multicolumn{2}{|c|}{$\begin{array}{c}(1) \\
\text { Dep. Var. } \\
=\operatorname{Pr}\left(U N D E R I N V_{t}=1\right)\end{array}$} & \multicolumn{2}{|c|}{$\begin{array}{c}(2) \\
\text { Dep. Var. } \\
=\operatorname{Pr}(\text { OVERINV } \\
=1)\end{array}$} \\
\hline & & Coeff. & z-stat. & Coeff. & z-stat \\
\hline INTERCEPT & & -1.704 & $-8.23 * * *$ & -1.725 & $-8.89 * * *$ \\
\hline
\end{tabular}




\begin{tabular}{|c|c|c|c|c|}
\hline$C P X G D_{t}$ & -0.185 & $-1.93^{*}$ & -0.406 & $-4.56 * * *$ \\
\hline INVEFF & -0.019 & $-6.24 * * *$ & -0.022 & $-7.39 * * *$ \\
\hline$E P S G D$ & -0.224 & $-2.02 * *$ & -0.283 & $-2.63 * * *$ \\
\hline$E P S G D * E P S G A C C$ & -2.064 & -1.11 & 2.295 & 0.85 \\
\hline INSTOWN & -0.434 & $-3.47 * * *$ & 0.092 & 0.78 \\
\hline$A N A L Y S T$ & -0.307 & $-3.70 * * *$ & -0.16 & $-2.08 * *$ \\
\hline$F R Q$ & -0.305 & -0.40 & -3.703 & $-6.69 * * *$ \\
\hline$L E V$ & 1.128 & $4.59 * * *$ & -1.124 & $-4.24 * * *$ \\
\hline FREECF & -0.062 & $-1.86^{*}$ & 0.074 & $3.04 * * *$ \\
\hline$S T D C P X$ & 0.001 & 0.50 & 0.005 & $3.22 * * *$ \\
\hline TOBINQ & 0.498 & $11.81 * * *$ & 0.142 & $3.45 * * *$ \\
\hline$C F_{t}$ & -0.01 & -0.95 & 0.019 & 1.48 \\
\hline$N$ & \multirow{2}{*}{\multicolumn{4}{|c|}{$\begin{array}{l}6,430 \\
0.080\end{array}$}} \\
\hline Pseudo $\mathrm{R}^{2}$ & & & & \\
\hline
\end{tabular}




\section{University Library}

\section{- M M I N E R VA A gateway to Melbourne's research publications}

Minerva Access is the Institutional Repository of The University of Melbourne

Author/s:

Bae, J;Biddle, G;Park, CW

Title:

Managerial Learning from Analyst Feedback to Voluntary Capex Guidance, Investment Efficiency and Firm Performance

Date:

2022-01-01

Citation:

Bae, J., Biddle, G. \& Park, C. W. (2022). Managerial Learning from Analyst Feedback to Voluntary Capex Guidance, Investment Efficiency and Firm Performance. Management Science, 68 (1), pp.583-687. https://doi.org/10.1287/mnsc.2020.3896.

Persistent Link:

http://hdl.handle.net/11343/251848 